
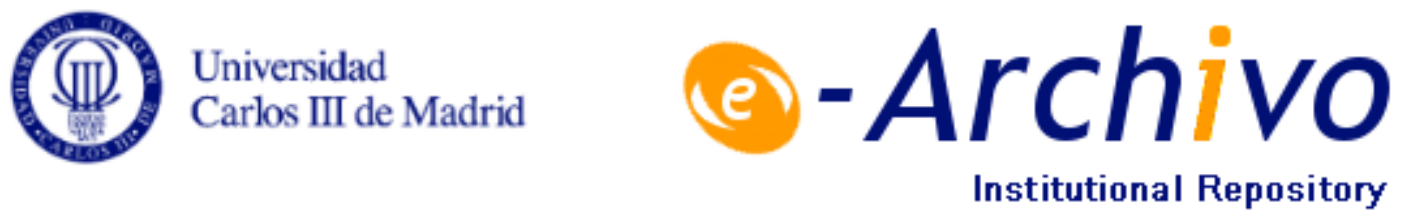

This is a postprint version of the following published document:

Santos, A.A.P., Nogales, F.J. y Ruiz, E. (2013). Comparing univariate and multivariate models to forecast portfolio Value-at-Risk. Journal of Financial Econometrics, v. 11, n. 2, pp. 400-441. Avalaible in: http://dx.doi.org/10.1093/ijfinec/nbs015

(C) Oxford University Press 


\title{
Comparing Univariate and Multivariate Models to Forecast Portfolio Value-at-Risk
}

\author{
ANDRÉ A. P. SANTOS \\ Universidade Federal de Santa Catarina \\ FRANCISCO J. NOGALES \\ Universidad Carlos III de Madrid \\ ESTHER RUIZ \\ Universidad Carlos III de Madrid
}

\begin{abstract}
This article compares multivariate and univariate Generalized Autoregressive Conditional Heteroskedasticity $(\mathrm{GARCH})$ models to forecast portfolio value-at-risk ( $\mathrm{VaR})$. We provide a comprehensive look at the problem by considering realistic models and diversified portfolios containing a large number of assets, using both simulated and real data. Moreover, we rank the models by implementing statistical tests of comparative predictive ability. We conclude that multivariate models outperform their univariate counterparts on an out-of-sample basis. In particular, among the models considered in this article, the dynamic conditional correlation model with Student's $t$ errors seems to be the most appropriate specification when implemented to estimate the VaR of the real portfolios analyzed. (JEL: C22, C53, G17)
\end{abstract}

KEYWORDS: backtesting, Basel Accords, market risk, composite likelihood, risk management

Market risk management has been receiving increased attention in the past few years due to the importance devoted by the Basel II and Basel III Accords to the regulation of the financial system. These Accords explicitly recognize the role of value-at-risk $(\mathrm{VaR})$ that financial institutions must implement and report in order

A. A. P. S. acknowledges financial support from research Projects CNPq Universal 481719/2011-3 and UFSC-Funpesquisa 2010/2011 from the Brazilian Government. F. J. N. is supported by the Spanish Government through Project MTM2010-16519. E. R. is supported by the Spanish Government ECO200908100. Address correspondence to André A. P. Santos, Department of Economics, Universidade Federal de Santa Catarina, Campus Universitário Reitor João David Ferrira Lima Trindade - Florianópolis - Santa Catarina - Brasil - CEP: 88040-970, or e-mail: andreportela@cse.ufsc.br 
to monitor their financial risk and to determine the amount of capital subject to regulatory control; see Berkowitz and O'Brien (2002). Consequently, VaR is now established as one of the most popular risk measures designed to control and manage market risk. The Basel Accords also establish penalties for inadequate models and, consequently, there are incentives to pursue accurate VaR estimates. A myriad of procedures are currently available for predicting the VaR, but no consensus has been reached on which procedure is best.

The first decision one has to make when trying to predict the VaR of a portfolio is whether to use a multivariate model for the system of individual asset returns or, alternatively, to use a univariate procedure for the portfolio returns. In this article, we assume known portfolio weights so that our focus is on whether the additional information incorporated in multivariate GARCH models compensate the additional uncertainty due to the large number of parameters to be estimated. One can possibly argue that modeling the joint dynamics of the assets contained in the portfolio via a multivariate model can lead to forecast improvements due to the use of more information. However, as the dimension of the portfolio increases, the usually large number of parameters involved renders the estimation of multivariate models more complicated, possibly compromising their predictive ability. Consequently, many authors conclude that it is probably better to adopt univariate models to estimate the VaR of a portfolio; see, for example, Berkowitz and O'Brien (2002), Brooks and Persand (2003), Bauwens, Laurent, and Rombouts (2006), Christoffersen (2009) and McAleer (2009). Recently, McAleer and da Veiga (2008) found mixed evidence about the comparative performance of univariate and multivariate models. However, the conclusions of these works are limited in several ways. First, they are based on portfolios composed of very few assets (usually three or four), while in real-world situations, financial institutions are usually faced with much larger portfolios. Second, they compare univariate and multivariate VaRs by using the backtesting tests based on coverage/independence criteria proposed by Kupiec (1995) and Christoffersen (1998). These tests, though appropriate to evaluate the accuracy of a single model, can provide an ambiguous decision about which candidate model is better. Therefore, it is interesting to enhance the backtesting analysis by using statistical tests designed to evaluate the comparative predictive performance among candidate models as, for example, the comparative predictive ability (CPA) test proposed by Giacomini and White (2006). Third, some of the works mentioned above only consider multivariate models with constant conditional correlations; see Brooks and Persand (2003) and McAleer and da Veiga (2008). There is, however, large evidence that, in practice, conditional correlations evolve over time and exhibit asymmetric effects; see, for example, Engle (2002), Tse and Tsui (2002) and Cappiello, Engle, and Sheppard (2006), among many others.

The goal of this article is to compare the performance of univariate and multivariate GARCH models when implemented to forecast the VaR of large portfolios. The comparison among the alternative models considered is done not only by using backtesting but also the CPA test. We also extend previous studies by considering multivariate models with asymmetric time-varying correlations 
and alternative distributions for the innovations. Our conclusions are based on the results of Monte Carlo experiments using several alternative specifications for the data-generating process (DGP) and on empirical evidence obtained by estimating the portfolio VaR of three real market portfolios containing a large number of assets. We show that even in large systems, it could be worth to predict the VaR of a portfolio by fitting multivariate models.

This article is organized as follows. Section 1 provides a brief description of the multivariate and univariate VaR models considered in this article. In Section 2, we compare both approaches using simulated data, while Section 3 is devoted to the comparison based on real portfolios. Section 4 concludes.

\section{UNIVARIATE AND MULTIVARIATE VAR MODELS}

In this section, we describe several alternative procedures to obtain portfolio VaR forecasts using univariate and multivariate procedures. Throughout the article, we focus on the portfolio VaR for a long position in which traders have bought the assets and wish to measure the risk associated to a decrease in their prices. Moreover, we consider an equally weighted portfolio, which has been extensively used in the empirical literature; see, for instance, Zaffaroni (2007) and DeMiguel, Garlappi, and Uppal (2009).

\subsection{VaR estimation}

Denote by $Y_{t}=\left(y_{1 t}, \ldots, y_{N t}\right)^{\prime}$ the vector of returns of the $N$ assets contained in the portfolio at time $t$ and by $y_{p, t}=W_{t-1}^{\prime} Y_{t}$ the portfolio return, where $W_{t-1}$ is the vector of portfolio weights, which is assumed to be known at time $t-1$. The portfolio VaR for a long position is defined as the $\vartheta$-quantile of the conditional distribution of the portfolio return $y_{p, t}$. This means that, with probability $\vartheta$, the portfolio return will be smaller than the VaR. Therefore, the VaR is defined as:

$$
\operatorname{VaR}_{t}^{\vartheta}=\sup \left[r \mid P\left(y_{p, t} \leq r\right) \leq \vartheta\right]
$$

where the probability $P$ is taken with respect to the distribution function of the portfolio returns conditional on the information available at time $t-1$.

Throughout the article we consider $\vartheta=1 \%$ which is the level that financial institutions must report as required by the Basel Accords. Additionally, in the simulations, we also consider $\vartheta=5 \%$ as this is the probability often considered in other related papers.

Next, we describe the alternative univariate and multivariate procedures considered in this article to estimate the VaR. First, the VaR can be estimated by implementing the univariate conditional autoregressive VaR (CAViaR) model proposed by Engle and Manganelli (2004), which specifies directly the dynamic 
evolution of the $\vartheta$-quantile rather than the distribution of the portfolio returns. The indirect GARCH specification of the CAViaR model is given by

$$
\operatorname{VaR}_{t}^{\vartheta}=\left[\omega+\alpha y_{p, t-1}^{2}+\beta\left(\operatorname{VaR}_{t-1}^{\vartheta}\right)^{2}\right]^{1 / 2} .
$$

Alternatively, when assuming a particular specification for the conditional mean and variance, the portfolio VaR is given by

$$
\operatorname{VaR}_{t}^{\vartheta}=\mu_{p, t}+\sigma_{p, t} q_{\vartheta},
$$

where $\mu_{p, t}$ and $\sigma_{p, t}$ are the portfolio conditional mean and standard deviation at time $t$, respectively, and $q_{\vartheta}$ is the $\vartheta$-quantile of the distribution of the centered and standardized returns, $\varepsilon_{p, t}=\left(y_{p, t}-\mu_{p, t}\right) / \sigma_{p, t}$. Therefore, to compute the VaR in (3), one needs to estimate $q_{\vartheta}, \mu_{p, t}$, and $\sigma_{p, t}$. These estimates can be obtained by considering two alternative conditioning sets available at time $t-1$. First, one can consider the distribution of portfolio returns conditional on past portfolio returns, i.e., the distribution of $y_{p, t}$ conditional on a linear combination of past asset returns, $y_{p, t-h}=W_{t-h-1}^{\prime} Y_{t-h}$. Alternatively, one can consider the distribution of $y_{p, t}$ conditional on the whole vector of past asset returns, $Y_{t-h}$. The former case leads to a univariate model for the portfolio returns while the latter leads to a multivariate model.

Consider first the computation of the quantile $q_{\vartheta}$ in (3). In the univariate case, two alternative conditional distributions are usually assumed: the Gaussian and the Student's $t$ distribution with $v$ degrees of freedom. Note that, when considering a Student's $t$ distribution, the $\vartheta$ - quantile in (3) is given by $q_{\vartheta}=\sqrt{\frac{v-2}{v}} \tilde{q}_{\vartheta}$, where $\tilde{q}_{\vartheta}$ is the $\vartheta$ - quantile of a Student's $t$ distribution with $v$ degrees of freedom; see Pesaran, Schleicher, and Zaffaroni (2009).

In the multivariate case, assuming a given multivariate distribution of returns, the corresponding conditional distribution of $\varepsilon_{p, t}$ is, in general, unknown. It only takes a tractable form when the distribution of returns is closed under linear transformations, i.e. when, for example, all linear combinations of $Y_{t}$ have the same distribution equal to the marginal distribution of returns. This is the case of the standardized multivariate Normal and Student's $t$ distributions; see Christoffersen (2009) and Pesaran, Schleicher, and Zaffaroni (2009). Therefore, in this article, we consider these two alternative multivariate specifications for the conditional distribution.

Finally, rather than assuming a particular distribution for $\varepsilon_{p, t}, q_{\vartheta}$ can be estimated as the $\vartheta$-quantile of its empirical distribution. This procedure, known as Filtered Historical Simulation (FHS) can be applied both to univariate and multivariate models; see Barone-Adesi, Bourgoin, and Giannopoulos (1998), Boudoukh, Richardson, and Whitelaw (1998), Hull and White (1998), and Christoffersen (2009) for a description.

Consider now the estimation of the conditional mean, $\mu_{p, t}$ in (3), which is assumed to be constant over time. In practice, the dynamic dependence in the 
conditional means of portfolio returns, when present, is very weak. Consequently, assuming a constant mean is not going to affect the results on the VaR estimation. Hence, throughout the article, we assume $\mu_{p}=E\left[y_{p, t} \mid y_{p, 1}, \ldots, y_{p, t-1}\right]$ and $\mu=$ $E\left(Y_{t} \mid Y_{1}, \ldots, Y_{t-1}\right)$, for all $t$. Note that $\mu_{p}=W_{t-1}^{\prime} \mu$.

Finally, the parametric specification of the VaR in (3) requires the estimation of the conditional variance of the portfolio. The specification of $\sigma_{p, t}^{2}$ depends on whether we consider a univariate or a multivariate model when conditioning on the past. When computing the VaR using a univariate model, $\sigma_{p, t}^{2}$ is given by the variance of portfolio returns conditional on past portfolio returns, i.e.,

$$
\sigma_{p, t}^{2}=E\left[\left(y_{p, t}-\mu_{p}\right)^{2} \mid y_{p, 1}, \ldots, y_{p, t-1}\right]
$$

In this case, four different univariate specifications for the conditional variance in (4) are considered: the GARCH model of Bollerslev (1986), the GlostenJagannathan-Runkle (GJR) model of Glosten, Jagannathan, and Runkle (1993), the exponential GARCH (EGARCH) model of Nelson (1991), and the asymmetric power ARCH (APARCH) model of Ding, Granger, and Engle (1993). All models are specified with their simplest forms, i.e., the variance only depends on one lag of past returns and past conditional variances, as they have shown to be the most relevant in empirical applications. Consequently, the GARCH model is given by:

$$
\sigma_{p, t}^{2}=\omega+\alpha y_{p, t-1}^{2}+\beta \sigma_{p, t-1}^{2}
$$

where $\omega>0, \beta, \alpha \geq 0$ and $\alpha+\beta<1$ to guarantee the positivity of conditional variances and the stationarity of returns. The GJR model is given by:

$$
\sigma_{p, t}^{2}=\omega+\alpha y_{p, t-1}^{2}+\beta \sigma_{p, t-1}^{2}+\delta I\left(\varepsilon_{p, t-1}<0\right) y_{p, t-1}^{2}
$$

where $I(\cdot)$ is the indicator function that takes value 1 when the argument is true. The GJR model incorporates the asymmetric response of volatility to positive and negative returns, known as leverage effect. The restriction to ensure positivity of $\sigma_{p, t}^{2}$ is $\omega>0, \alpha, \beta, \delta \geq 0$. The model is stationary if $\delta<2(1-\alpha-\beta)$; see Hentschel (1995). The EGARCH model also incorporates the leverage effect and it is given by:

$$
\ln \left(\sigma_{p, t}^{2}\right)=\omega+\alpha\left(\left|\varepsilon_{p, t-1}\right|-E\left|\varepsilon_{p, t-1}\right|\right)+\delta \varepsilon_{p, t-1}+\beta \ln \left(\sigma_{p, t-1}^{2}\right) .
$$

Rather than specifying the variance directly, the EGARCH model specifies the natural logarithm of the variance and, consequently, the parameters are not restricted to ensure the positivity of the conditional variance. The stationarity condition is $|\beta|<1$ if $\varepsilon_{p, t}$ is Gaussian; see Straumann and Mikosch (2006) for a general condition. Note that the value of $E\left|\varepsilon_{p, t-1}\right|$ depends on the assumed distribution of $\varepsilon$. For the standard Gaussian distribution, $E\left|\varepsilon_{p, t-1}\right|=\sqrt{2 / \pi}$ whereas 
for the Student's $t$ distribution, $E\left|\varepsilon_{p, t-1}\right|=2 \sqrt{v-2} \Gamma((v+1) / 2) /(v-1)(\Gamma(v / 2))$ where $\Gamma(\cdot)$ is the gamma function. Finally, the APARCH model is given by:

$$
\sigma_{p, t}^{\lambda}=\omega+\alpha\left(\left|\varepsilon_{p, t-1}\right|+\delta \varepsilon_{p, t-1}\right)^{\lambda}+\beta \sigma_{p, t-1}^{\lambda} .
$$

The APARCH model differs from the previous asymmetric specifications by directly parameterizing the nonlinearity in the conditional variance via the parameter $\lambda$. To ensure that $\sigma_{p, t}^{\lambda}$ is nonnegative, it is necessary that $\omega \geq 0, \alpha \geq 0$ and $-1 \leq \delta \leq 1$; see Ding, Granger, and Engle (1993) for stationarity conditions.

On the other hand, when computing the VaR using a multivariate model, $\sigma_{p, t}^{2}$ is given by the variance of the portfolio returns conditional on past returns, i.e.,

$$
\sigma_{p, t}^{2}=E\left[\left(y_{p, t}-\mu_{p}\right)^{2} \mid Y_{1}, \ldots, Y_{t-1}\right]=W_{t-1}^{\prime} H_{t} W_{t-1},
$$

where $H_{t}=E\left[\left(Y_{t}-\mu\right)\left(Y_{t}-\mu\right)^{\prime} \mid Y_{1}, \ldots, Y_{t-1}\right]$ is the positive-definite conditional covariance matrix of $Y_{t}$.

To describe the dynamics of the conditional covariance matrix, $H_{t}$, we consider models based on the decomposition of the conditional covariance matrix into conditional standard deviations and correlations as follows:

$$
H_{t}=D_{t} R_{t} D_{t}
$$

where $D_{t}=\operatorname{diag}\left(h_{1 t}^{1 / 2} \ldots h_{N t}^{1 / 2}\right)$ with $\operatorname{diag}(\cdot)$ being the operator that transforms a $N \times 1$ vector into a $N \times N$ diagonal matrix, and $h_{j t}$ is the conditional variance of the $j$-th return which can be specified by one of the parametric univariate models described above. The $N \times N$ matrix, $R_{t}$, is a symmetric positive-definite conditional correlation matrix with elements $\rho_{i j, t}$, where $\rho_{i i, t}=1$. We consider three different specifications for $R_{t}$ : the constant conditional correlation (CCC) model of Bollerslev (1990), the dynamic conditional correlation (DCC) model of Engle (2002), and the asymmetric DCC (AsyDCC) model of Cappiello, Engle, and Sheppard (2006).

The CCC model assumes that the conditional correlation matrix $R_{t}$ is constant over time. In the DCC model, the conditional correlation matrix $R_{t}$ is given by:

$$
R_{t}=\operatorname{diag}\left(Q_{t}^{-1 / 2}\right) Q_{t} \operatorname{diag}\left(Q_{t}^{-1 / 2}\right)
$$

where $\operatorname{diag}\left(Q_{t}\right)$ is a diagonal matrix containing the diagonal elements of the $N \times N$ positive-definite matrix $Q_{t}$ given by

$$
Q_{t}=(1-\alpha-\beta) \bar{Q}+\alpha \epsilon_{t-1} \epsilon_{t-1}^{\prime}+\beta Q_{t-1}
$$

where $\bar{Q}$ is the $N \times N$ unconditional covariance matrix of $\epsilon_{t}=H_{t}^{-1 / 2}\left(Y_{t}-\mu\right)$, and $\alpha$ and $\beta$ are nonnegative scalar parameters. The model is covariance-stationary if $\alpha+\beta<1$. Moreover, $Q_{t}$ is guaranteed to be positive definite if $(1-\alpha-\beta) \bar{Q}$ and $Q_{0}$ are themselves positive definite. 
Finally, the AsyDCC model incorporates the leverage effect into the conditional correlations. It is given by:

$$
Q_{t}=(1-\alpha-\beta) \bar{Q}-\delta \bar{\Gamma}+\alpha \epsilon_{t-1} \epsilon_{t-1}^{\prime}+\beta Q_{t-1}+\delta n_{t-1} n_{t-1}^{\prime}
$$

where $n_{t}=I\left(\epsilon_{t}<0\right) \odot \epsilon_{t}$ and $\bar{\Gamma}=E\left[n_{t} n_{t}^{\prime}\right]$. A necessary condition for $Q_{t}$ to be covariance-stationary and positive definite is that $(1-\alpha-\beta) \bar{Q}-\delta \bar{\Gamma}$ and $Q_{0}$ are positive definite and $\alpha+\beta+\lambda \delta<1$, where $\lambda$ is the maximum eigenvalue of $\bar{Q}^{-1 / 2} \bar{\Gamma} \bar{Q}^{-1 / 2}$.

As noted above, the multivariate models are implemented using alternative specifications for the univariate conditional variances. To facilitate the exposition of the results, we denote by CCC-GARCH, CCC-GJR, CCC-EGARCH, and CCC-APARCH the CCC model implemented with GARCH, GJR, EGARCH, and APARCH univariate conditional variances, respectively. The same notation applies to the DCC and AsyDCC models. This flexible modeling strategy allows the estimation of twelve alternative multivariate models.

Finally, it is worth to wonder whether the multivariate conditional heteroskedasticity in the vector $Y_{t}$, measured by $H_{t}$, is related with the univariate conditional heteroskedasticity of the portfolio return, $y_{p, t}$, given in expression (4). Note that the latter is obtained after contemporaneous aggregation of the returns in the portfolio. When the multivariate conditional covariance matrix, $H_{t}$, is represented by a GARCH model, the results of Nijman and Sentana (1996), derived for a bivariate portfolio, explain why conditional heteroskedasticity can also be found in the univariate portfolio returns. However, in this article, we are interested in large portfolios. In this sense, Zaffaroni (2007) has extended the results in Nijman and Sentana (1996) by considering the limiting behavior of linear combinations of returns. He shows that dynamic conditional heteroskedasticity is only preserved when the individual returns are sufficiently cross-correlated. However, unlike the finite $N$ case of Nijman and Sentana (1996), the linear combination of infinite assets is not a weak GARCH model although it displays dynamic univariate conditional heteroskedasticity.

\subsection{Forecast evaluation of VaR models}

The forecast evaluation of VaR models is usually done by backtesting using the unconditional and conditional coverage and independence tests proposed by Kupiec (1995) and Christoffersen (1998). However, as mentioned earlier, these tests are not appropriate for ranking alternative estimates of the VaR. Consequently, on top of evaluating whether each of the estimated VaRs are adequate, we also compare and rank them by implementing the CPA test of Giacomini and White (2006), which can be applied to the comparison between nested and nonnested models and among several alternative estimation procedures. The CPA test is implemented using the 
following asymmetric linear (tick) loss function of order $\vartheta$ :

$$
\mathcal{L}^{\vartheta}\left(e_{t}\right)=\left(\vartheta-I\left(e_{t}<0\right)\right) e_{t}
$$

where $e_{t}=y_{p, t}-\operatorname{VaR}_{t}^{\vartheta}$. The loss function in (14) is the implicit loss function whenever the object of interest is a forecast of a particular $\vartheta$-quantile; see Giacomini and Komunjer (2005). ${ }^{1}$ Consequently, finding the model that minimizes (14) is an intuitive and appealing criterion to compare predictive ability.

A Wald-type test is conducted as follows:

$$
C P A^{\vartheta}=T\left(T^{-1} \sum_{t=1}^{T-1} \mathcal{I}_{t} \mathcal{L} \mathcal{D}_{t+1}^{\vartheta}\right)^{\prime} \hat{\Omega}^{-1}\left(T^{-1} \sum_{t=1}^{T-1} \mathcal{I}_{t} \mathcal{L} \mathcal{D}_{t+1}^{\vartheta}\right)
$$

where $T$ is the sample size, $\mathcal{L} \mathcal{D}_{t}^{\vartheta}$ is the loss difference between the two models, and $\hat{\Omega}$ is a matrix that consistently estimates the variance of $\mathcal{I}_{t} \mathcal{L D}_{t+1}^{\vartheta}$. Following Giacomini and White (2006), we assume $\mathcal{I}_{t}=\left(1, \mathcal{L D}_{t}^{\vartheta}\right)$. The null hypothesis of equal predictive ability is rejected for a size $\xi$ when $\mathrm{CPA}^{\vartheta}>\chi_{T, 1-\xi}^{2}$.

\section{MONTE CARLO EVIDENCE}

In this section, we perform Monte Carlo experiments in order to compare the insample and out-of-sample performances of multivariate versus univariate models. A major concern when performing this kind of experiments is the choice of the DGP. Consequently, we consider three alternative DGPs different from any of the models implemented for the estimation of the VaR. In this way, we do not favor any particular multivariate specification.

First, we generate data by the orthogonal GARCH (O-GARCH) model of Alexander and Chibumba (1997) and Alexander (2001), extended to incorporate leverage effects in the dynamics of the common factors. The second DGP considered is a multivariate autoregressive stochastic volatility (MARSV) model; see Harvey, Ruiz, and Shephard (1994) and Asai, McAleer, and Yu (2006). Finally, we simulate an asymmetric version of the diagonal VEC (ASYDVEC) model of Bollerslev, Engle, and Woodridge (1988) proposed by Engle and Sheppard (2008). In all cases, we consider a Gaussian distribution for the conditional distribution of the simulated

\footnotetext{
${ }^{1}$ To see how the tick loss function works in practice, consider a simple example involving two different $\mathrm{VaR}$ models. Suppose that the portfolio return in day $t$ is $-4 \%$ and that the VaR in day $t$ (forecasted in $t-1$ ) obtained from the two models are $-2 \%$ and $-6 \%$, respectively. Obviously, for the first model, there is a VaR violation whereas for the second there is not. For the first model, the value of the tick loss function in $(14)$ is $(0.01-1)(-2) \cong 2$ whereas for the second model the value is $(0.01-0) 2=0.02$. (Recall that, since we are considering only a long position in the portfolio, the VaR will be always a negative number). Therefore, according to the tick loss function, a model is more penalized when a VaR violation is observed. Moreover, the greater is the magnitude of the violation the greater is the penalization.
} 
returns. The details about the parametrization of the three DGPs considered are given in the Appendix.

Our Monte Carlo experiments are as follows. For each of the three DGPs considered, we generate 100 systems of $N=10$ asset returns, each with a sample size of $T=5000$ observations. Then, the first 2500 observations are used to estimate the parameters of each of the univariate and multivariate models described in Section 1 and the corresponding VaR for $\vartheta=5 \%$ and $\vartheta=1 \%$.

The univariate GARCH, GJR, EGARCH, and APARCH models are estimated by quasi maximum likelihood (QML) using the Oxford MFE Matlab Toolbox by Kevin Sheppard ${ }^{2}$, restricting the parameters to satisfy the positivity and stationarity conditions when appropriate; see Straumann and Mikosch (2006) and Francq and Zakoian (2009) for the asymptotic distribution of these estimators. The parameters of the CAViaR model in (2) are estimated using regression quantiles as in Engle and Manganelli (2004) and Koenker (2005). The VaR estimated by FHS is based on the GARCH specification of the conditional variance.

The CCC model is estimated in two steps. First, univariate models are fitted to estimate the conditional variances of each return in the system and then, the correlation matrix is estimated using the sample correlations among the standardized returns. The multivariate DCC models are estimated by the composite likelihood (CL) estimator proposed by Engle, Shephard, and Sheppard (2008) that considers all contiguous pairs of data ${ }^{3}$. Engle, Shephard, and Sheppard (2008) also provide asymptotic properties of the CL estimator. All models are estimated assuming Gaussian errors. Similarly, the quantile $q_{\vartheta}$ in (3) is obtained assuming a Normal distribution when necessary.

For the VaR computed by each of the univariate and multivariate procedures, we compute the average coverage and perform the unconditional coverage, independence, and conditional coverage tests both in-sample and out-of-sample. Consider first the in-sample results. For each of the three DGPs, the top panels of Tables 1-3 report, respectively, the in-sample Monte Carlo averages and standard deviations of the empirical coverages together with the number of rejections of the null hypothesis mentioned above when the nominal size is $10 \%$. Consider first the results of the empirical coverages. Tables 1-3 show that, regardless of the DGP and the VaR level, the average empirical coverages are very close to the nominal level for all the procedures implemented to estimate the VaR. The only remarkable difference among procedures appears when looking at the Monte Carlo standard deviations of the CAViaR and FHS estimators. In the former case, the standard deviation is clearly smaller (around ten times) than the others while in the latter, we observe larger deviations (around twice). Therefore, attending to the empirical coverage results, it seems that the univariate $\mathrm{CAViaR}$ model perform the best among the procedures considered to estimate the VaR, while the FHS performs the worst.

\footnotetext{
${ }^{2}$ http://www.kevinsheppard.com/wiki/MFE_Toolbox

${ }^{3}$ In this case, we have developed our own implementation in Matlab.
} 


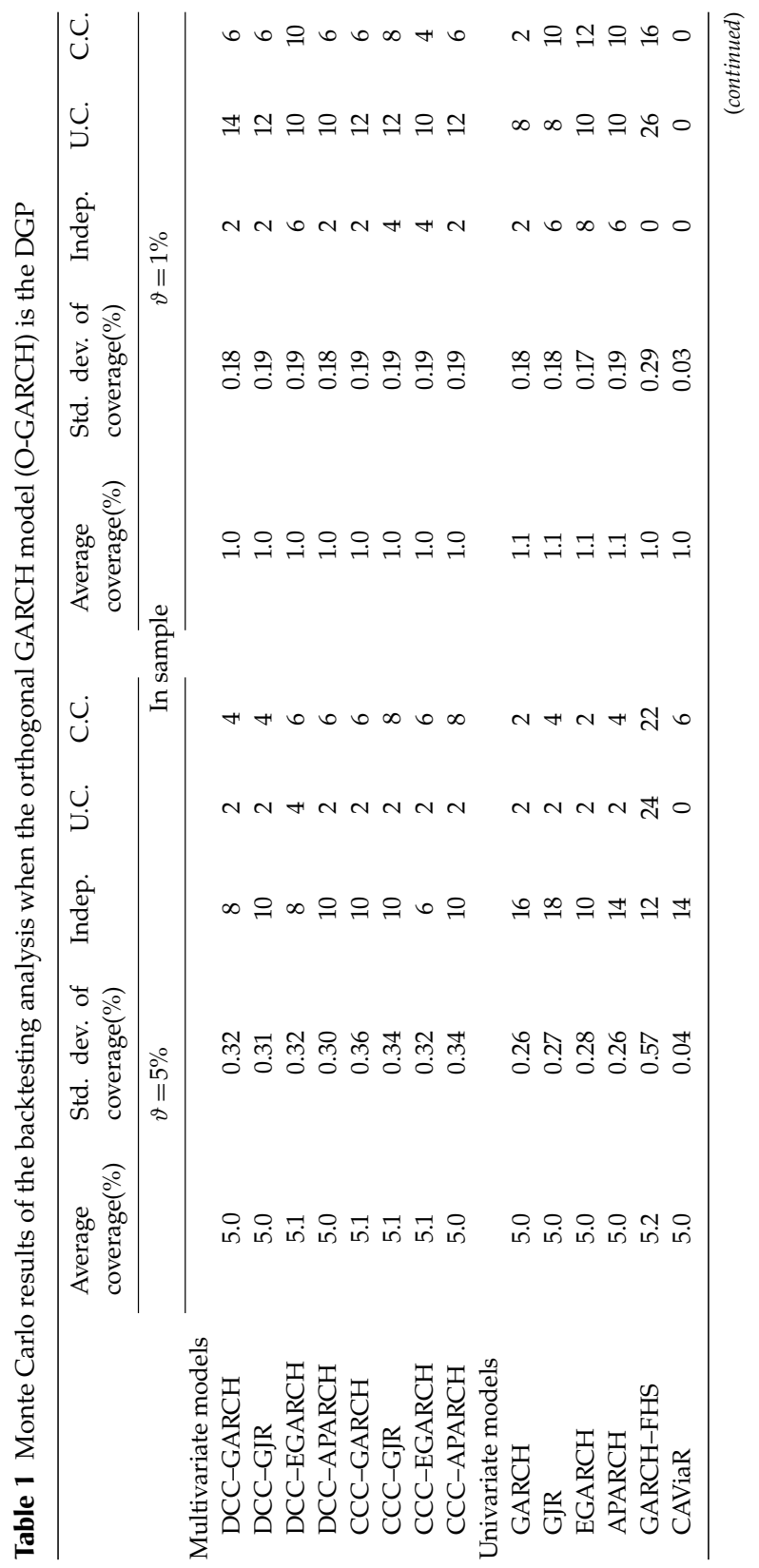




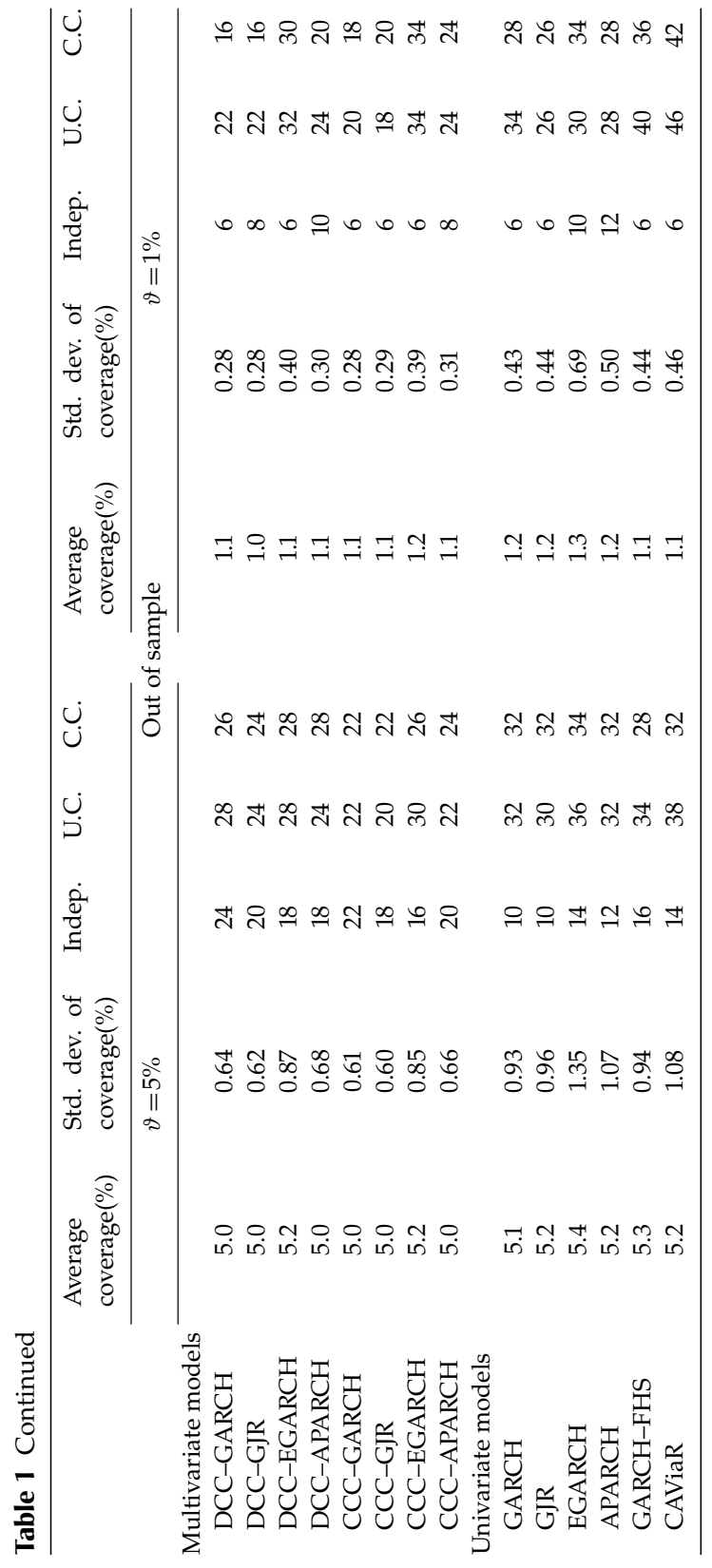




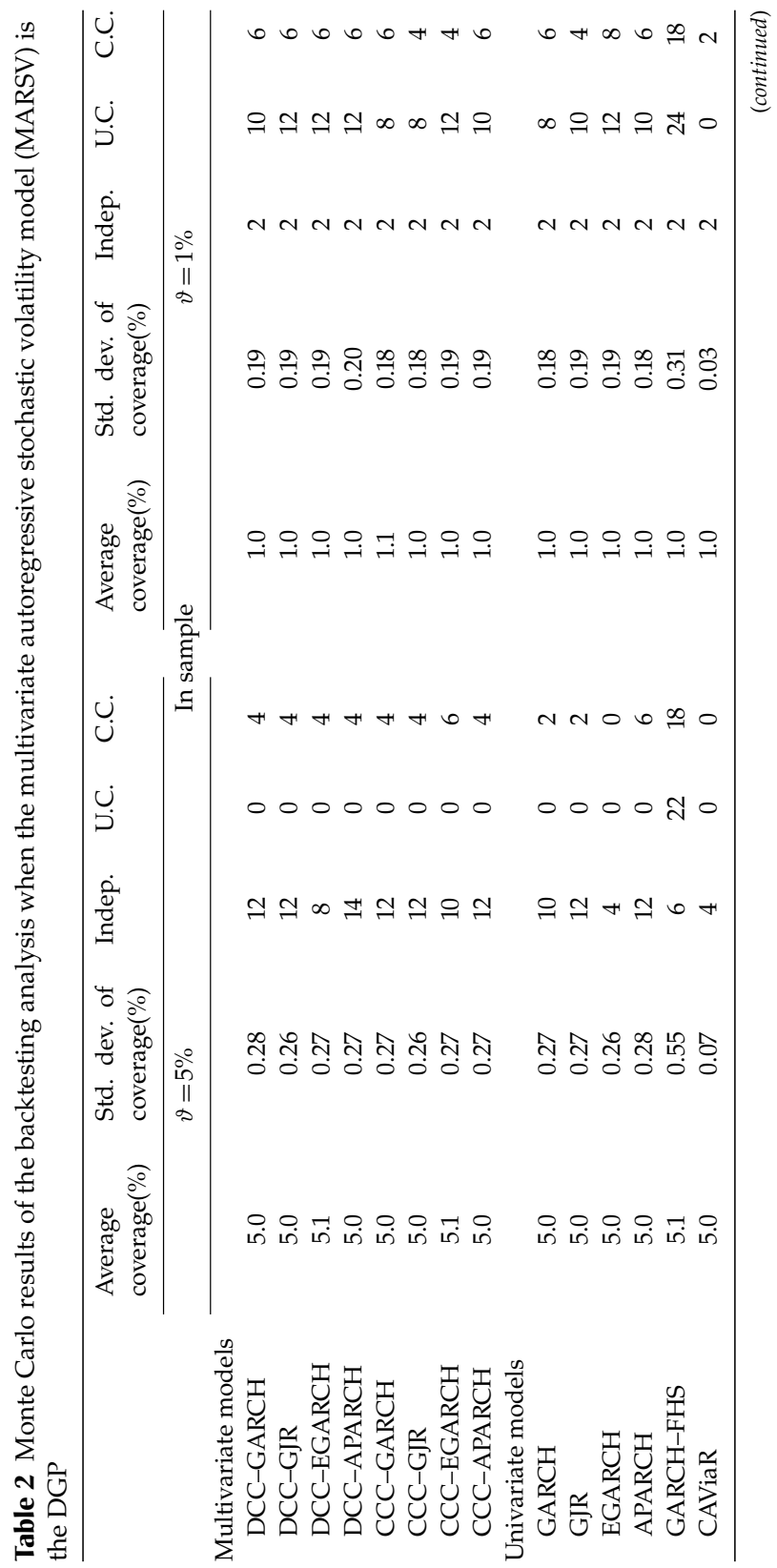




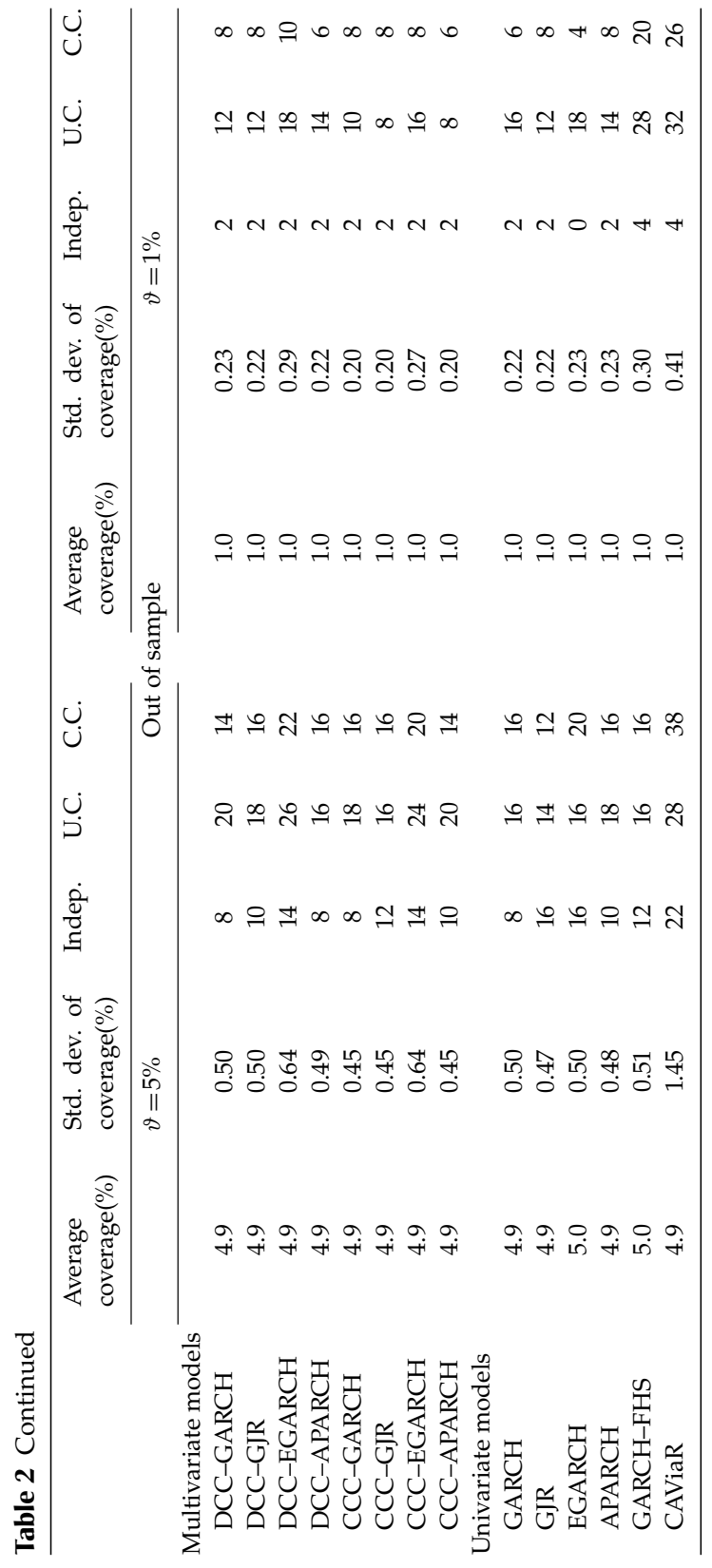




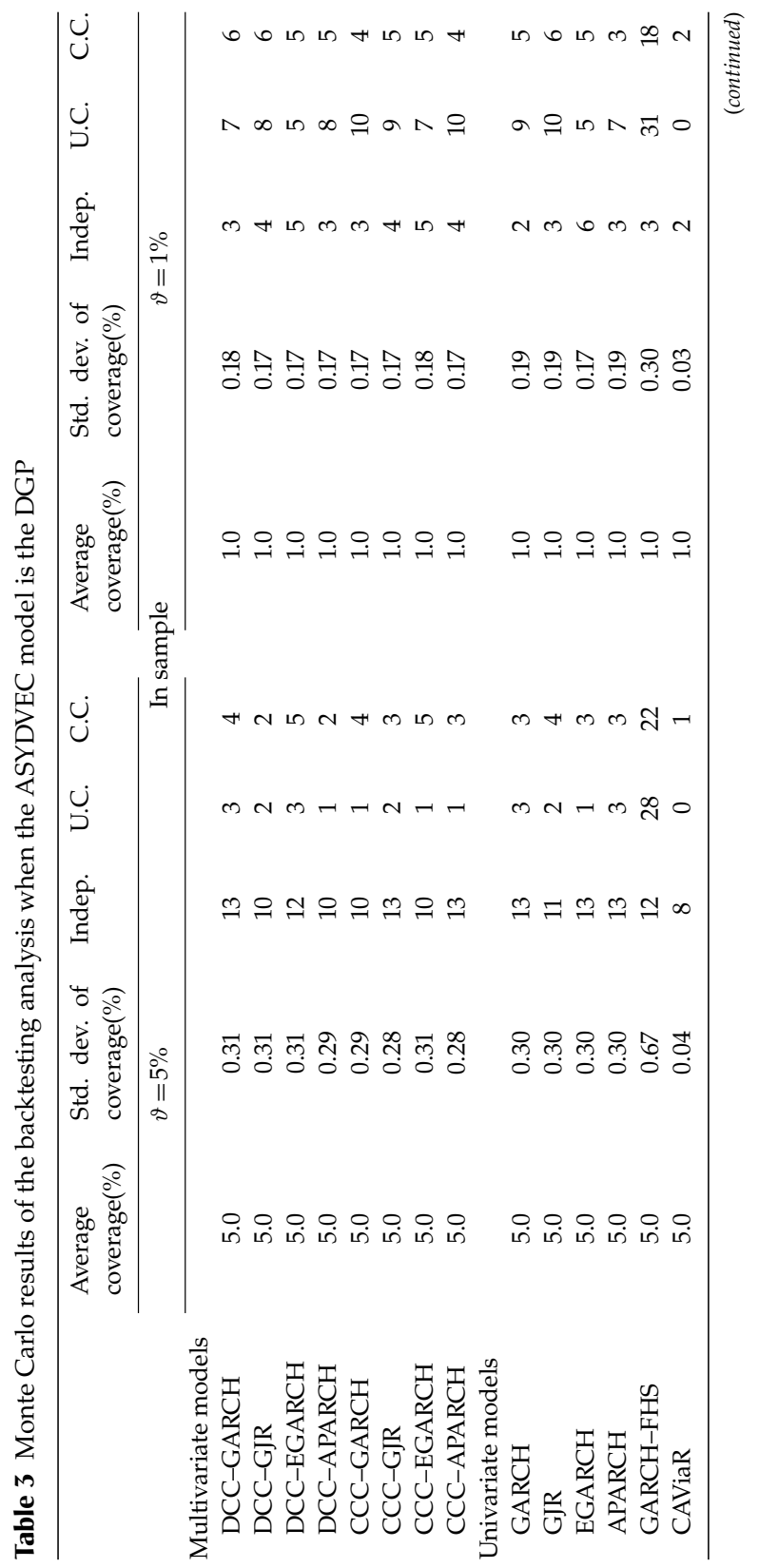




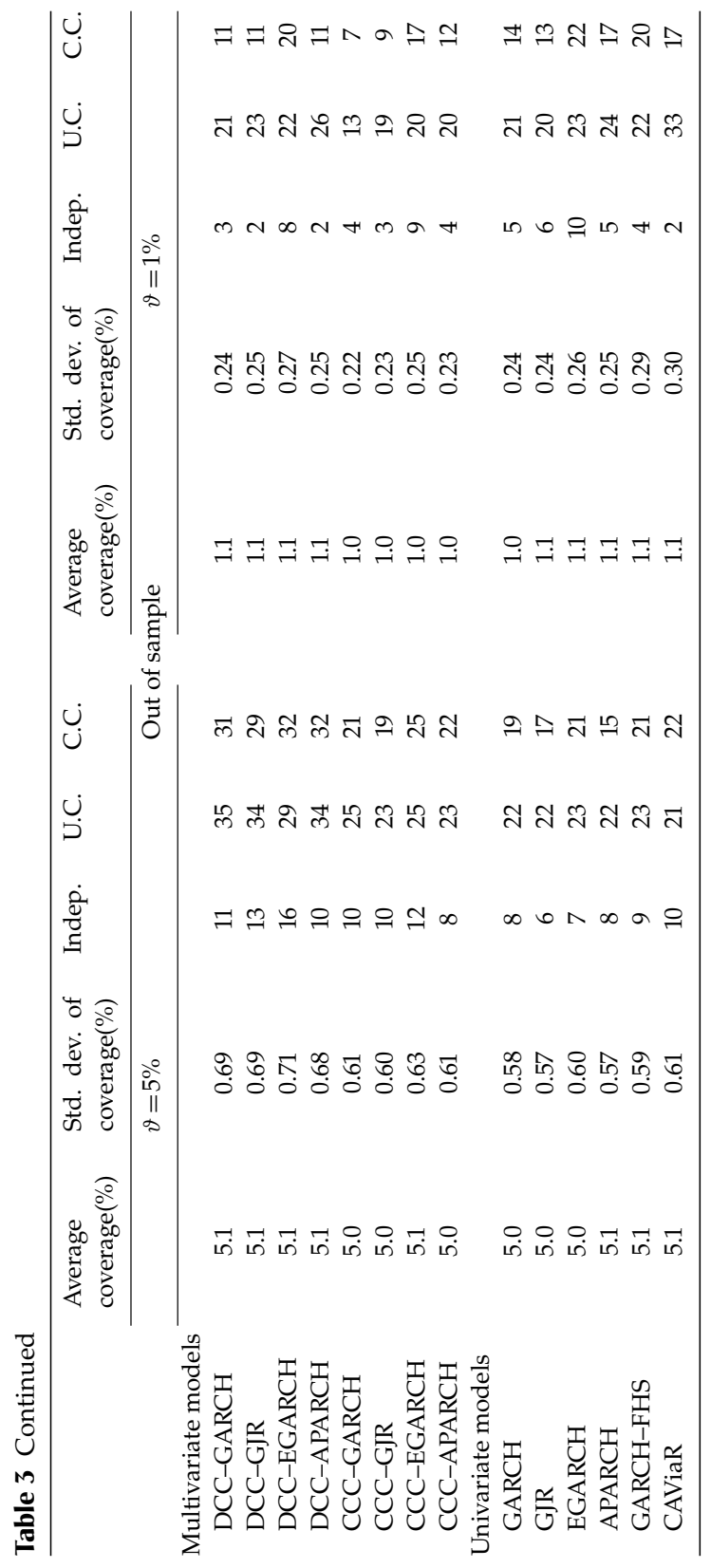


The bad performance of the FHS procedure is also clear when analyzing the number of rejections of the unconditional and conditional coverage tests, which are larger (around twice) than for the other procedures implemented, and clearly larger than the nominal size of $10 \%$. When looking at the number of rejections of the independence, unconditional and conditional coverage tests for all the other procedures, we observe they are either smaller or close to the nominal size. Therefore, from these tests we cannot conclude about different performances among the in-sample VaR estimates.

As mentioned above, these tests are not useful to compare procedures. Consequently, for each of the DGPs considered, the top panels of Tables 4-6 report, respectively, the in-sample number of times the CPA test prefers one of the two models being compared. Specifically, in each entry of these tables, the first number corresponds to the number of times the univariate model in the column outperforms the multivariate model in the row. The second number corresponds to the number of times the multivariate model outperforms the univariate model. In the remaining cases, the test is indifferent between both models. The results of this test are not completely conclusive and depend on the particular DGP considered. For instance, when considering the O-GARCH model as DGP, the top panel of Table 4 shows that the test is indifferent between the univariate and multivariate specifications in approximately $60 \%$ of the simulations. However, if $\vartheta=5 \%$ and the CPA test prefers one model, this model corresponds always to a multivariate specification. If $\vartheta=1 \%$, the test prefers more the multivariate specifications (around $40 \%$ of the time) although the univariate ones are chosen a few times (less than $10 \%$ of the time). However, the results are different when we consider the MARSV as DGP. From the top panel of Table 5, we can observe that the CPA test is indifferent in approximately $80 \%$ of the simulations. Furthermore, when one procedure is preferred, it is more often an univariate specification rather than a multivariate one. Only the FHS procedure is never chosen, in concordance with the results commented above on the empirical coverages. Finally, when the DGP is the ASYDVEC model, there is also a large number of times, between $70 \%$ and $80 \%$, in which the CPA test is indifferent. In this case, when one of the models is chosen, the test prefers roughly the same number of times a univariate or a multivariate procedure.

Therefore, the in-sample comparison between univariate and multivariate procedures to estimate the VaR has mixed results depending on the DGP considered. The only procedure that seems to be clearly rejected is the FHS one. To better appreciate the differences, we also carry out an out-of-sample VaR comparison where the parameters are estimated using the first 2500 observations and the remaining 2500 observations are used to compute one-step-ahead VaR forecasts. As with the in-sample comparison, the bottom panels of Tables 1-3 report the corresponding Monte Carlo averages and standard deviations of the empirical coverages together with the number of rejections of the null hypothesis for the independent, unconditional coverage and conditional coverage tests. Observing the average empirical coverages, the conclusions are similar to those obtained in 
the in-sample analysis, as these coverages are very close to the nominal VaR levels. However, when the DGP is the O-GARCH model, the standard deviations of the empirical coverages of the univariate procedures are clearly larger (around twice) than those of the multivariate ones. For the other two DGPs, the standard deviations are roughly similar regardless of the procedure implemented to estimate the VaR.

When analyzing the rejections of the independence, unconditional and conditional coverage tests, we can observe that, for the latter two tests, the rejections are larger than the nominal size of $10 \%$, while for the former one they are usually smaller. In any case, there are not relevant differences between the results corresponding to univariate and multivariate procedures. Therefore, as with the insample analysis, when analyzing the empirical coverages and the backtesting tests there is not a clear conclusion about which procedure could be more appropriate.

Consider now the results of the CPA test implemented to compare the outof-sample VaR estimates reported in the bottom panels of Tables 4-6 for each of the three DGPs considered, respectively. Regarding the results when the systems are generated by the O-GARCH model, we can observe that the number of times when the CPA test is indifferent is now smaller than in the in-sample comparison, being around $40 \%$. Furthermore, the multivariate procedures are clearly preferred when compared with the univariate ones. Finally, the results for the MARSV and ASYDVEC processes are similar. The CPA test is indifferent in approximately $75 \%$ of the cases. However, when looking at the results for the $\vartheta=1 \% \mathrm{VaR}$ level required by the Basel Accord, it is clear that if a model is chosen, then it is usually a multivariate model.

Therefore, we can summarize the Monte Carlo results by noting that the usual backtesting procedures give mixed results when comparing univariate and multivariate procedures to estimate the VaR regardless of whether the comparison is made in- or out-of-sample. In this sense, the results are in concordance with those obtained by McAleer and da Veiga (2008). However, when implementing the CPA test, we observe that it is indifferent in many cases but, when it chooses a model, most of the time this model has a multivariate specification. The preference of the CPA test for multivariate specifications is clearer out-of-sample.

The Monte Carlo results suggest that multivariate and univariate models deliver different estimates of the portfolio conditional variance and, consequently, different estimates of the portfolio VaR. Furthermore, the results are in favor of the multivariate approach. This difference can be explained by the fact that univariate models impose parameter restrictions that limits the dynamics represented by the multivariate models. The added flexibility of multivariate models translates into to more accurate estimates of the portfolio VaR. Therefore, if parameters are known, this additional flexibility allows us to explain why multivariate models work better. In practice, parameters need to be estimated, which ends up adding additional uncertainty to multivariate models in comparison to the their less parameterized univariate counterparts. According to our results, this uncertainty due to a larger number of estimated parameters does not compensate the gains coming from a better representation of the volatility dynamics in multivariate models. 


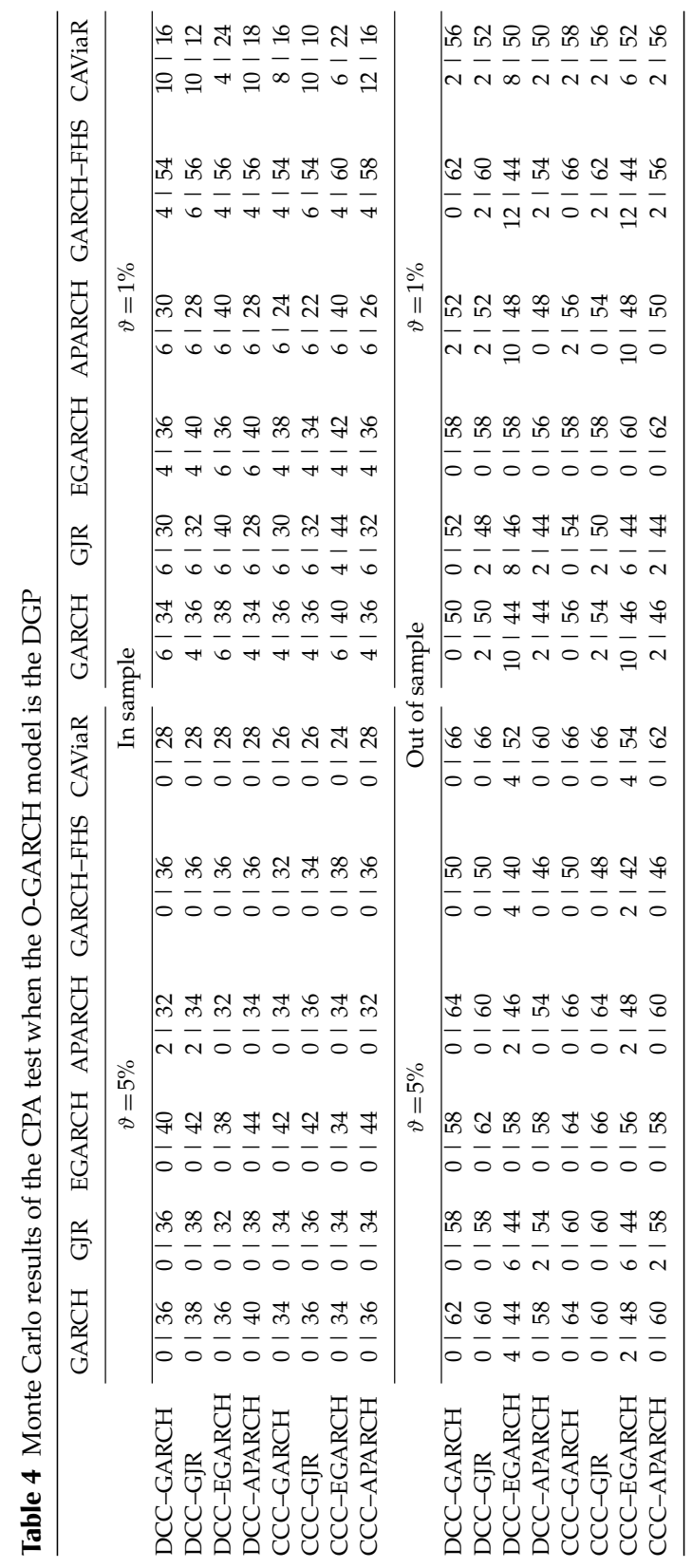




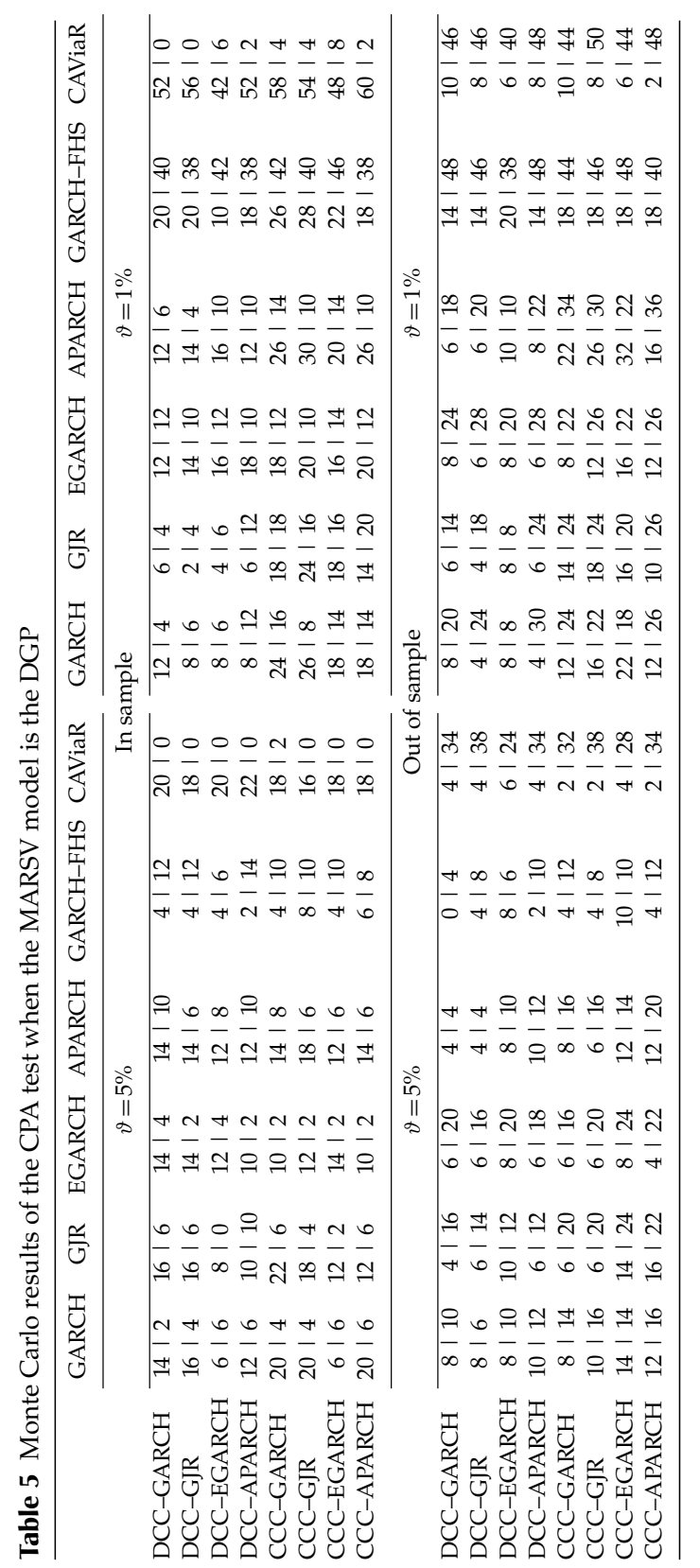




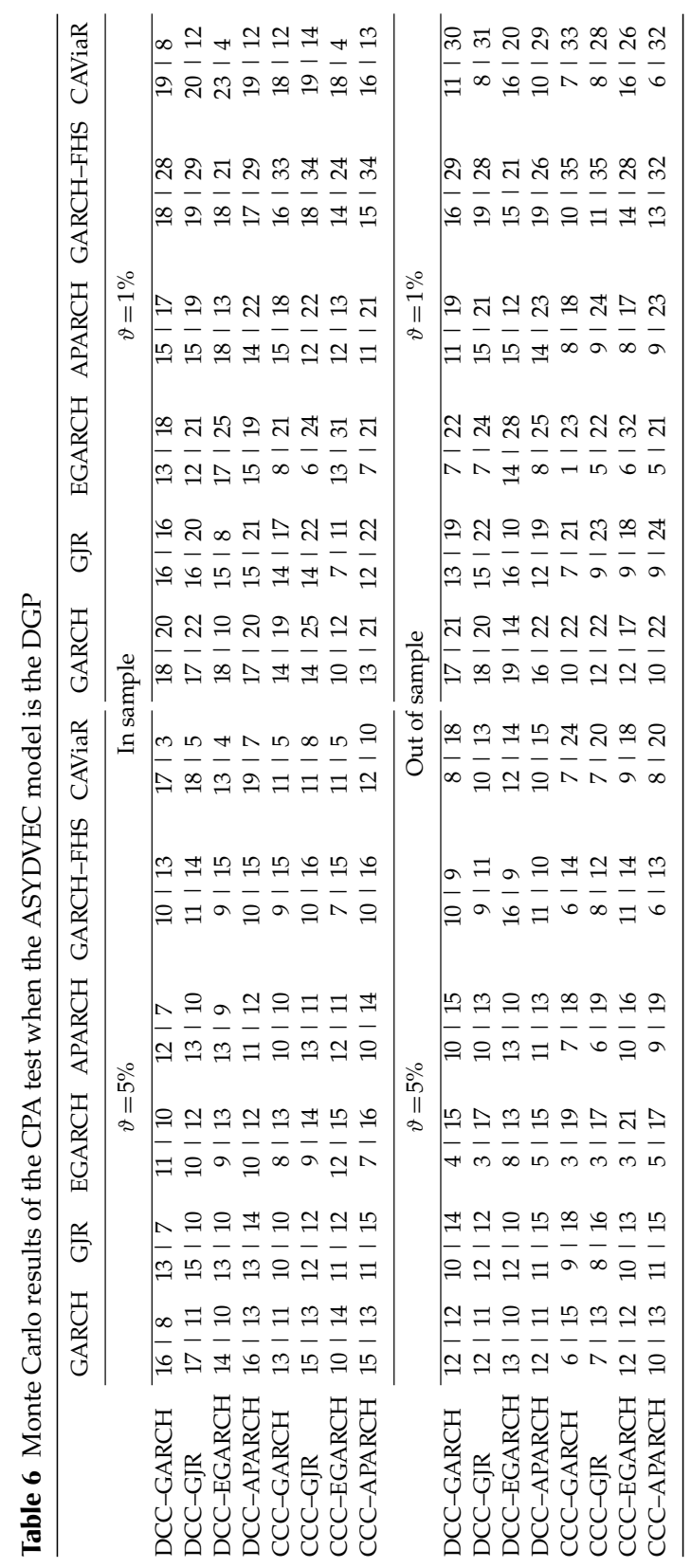




\section{EMPIRICAL EVALUATION WITH REAL MARKET DATA}

In this section, we compare empirically the multivariate and univariate models described above by implementing them to forecast the one-day-ahead VaR of a long position in equally weighted diversified portfolios with a very large number of assets. This is a realistic situation faced in most financial institutions. Moreover, we focus on the estimation of the portfolio $1 \%$-VaR, which is the relevant level for risk financial institutions which must report this level to measure their market risk exposure in accordance to the Basel Accords.

We analyze three real market portfolios of daily returns observed from January 3, 2000 to June 30, 2010, with $T=2639$. The first 1639 observations correspond to the in-sample period whereas the remaining 1000 observations correspond to the out-of-sample period. The first portfolio analyzed is composed of returns of forty-eight US industry portfolios. ${ }^{4}$ The second portfolio is composed of returns on twenty-five portfolios of stocks formed on the basis of size and bookto-market. These two data sets were downloaded from the web page of Kenneth French. ${ }^{5}$ Finally, the third portfolio considered is composed of returns of all stocks belonging to the S\&P100 index with common available observations during the sample period. This yields a total of seventy-seven stocks. This third portfolio was downloaded from the Reuters Ecowin database.

The top panel of Table 7 reports, for each of the three data sets and across the assets composing each of them, the average mean return (in \%), maximum and minimum return (in \%), standard deviation (in \%), skewness, and kurtosis, using data corresponding to the in-sample (first 1639 observations, from January 3, 2000 to July 11, 2006) and out-of-sample periods (last 1000 observations, from July 12, 2006 to June 30,2010$)$. We can observe that the mean return of the three portfolios is smaller in the out-of-sample period, which covers the financial crisis. On the other hand, the standard deviations are larger in the out-of-sample period. In all cases, the kurtosis are clearly greater than 3 . Finally, with the exception of the industry portfolio, the skewness coefficients are negative and larger (in size) in the out-of-sample period.

In the same way, the lower panel of Table 7 reports a summary of the sample moments of the univariate portfolio returns corresponding to the equally weighted portfolio for each of the three data sets. Because this is a well-diversified portfolio, the realized returns are less extreme and hence, the standard deviations (for each

\footnotetext{
${ }^{4}$ The industry sectors included in the portfolio are: agriculture, food products, candy and soda, beer and liquor, tobacco products, recreation, entertainment, printing and publishing, consumer goods, apparel, healthcare, medical equipment, pharmaceutical products, chemicals, rubber and plastic products, textiles, construction materials, construction, steel, fabricated products, machinery, electrical equipment, automobiles and trucks, aircraft, shipbuilding and railroad equipment, defense, precious metals, non metallic and industrial metal mining, coal, petroleum and natural gas, utilities, communication, personal services, business services, computers, electronic equipment, measuring and control equipment, business supplies, shipping containers, transportation, wholesale, retail, restaurants/hotels/motels, banking, insurance, real estate, trading, and other (sanitary services, steam, air-conditioning supplies, irrigation systems, and cogeneration).

${ }^{5}$ http://mba.tuck.dartmouth.edu/pages/faculty/ken.french/
} 
Table 7 Descriptive statistics for the three portfolios

\begin{tabular}{|c|c|c|c|}
\hline & Industry portfolios & S\&P100 stocks & Size-B/M portfolios \\
\hline & \multicolumn{3}{|c|}{ Multivariate data } \\
\hline \multicolumn{4}{|l|}{ In sample } \\
\hline Mean return(\%) & 0.095 & 0.013 & 0.043 \\
\hline Max. mean return $(\%)$ & 0.218 & 0.120 & 0.083 \\
\hline Min. mean return (\%) & -0.006 & -0.104 & -0.011 \\
\hline Mean std. dev. (\%) & 1.299 & 2.159 & 1.204 \\
\hline Max. std. dev. (\%) & 3.173 & 5.135 & 1.646 \\
\hline Min. std. dev. (\%) & 0.546 & 1.394 & 0.892 \\
\hline Mean kurtosis & 12.599 & 18.822 & 5.330 \\
\hline Max. kurtosis & 228.841 & 262.114 & 8.431 \\
\hline Min. kurtosis & 3.834 & 3.998 & 3.414 \\
\hline Mean skewness & 0.413 & -0.568 & -0.089 \\
\hline Max. skewness & 9.158 & 0.684 & 0.330 \\
\hline Min. skewness & -0.794 & -10.136 & -0.526 \\
\hline \multicolumn{4}{|l|}{ Out of sample } \\
\hline Mean return (\%) & 0.048 & -0.022 & 0.010 \\
\hline Max. mean return $(\%)$ & 0.092 & 0.065 & 0.046 \\
\hline Min. mean return (\%) & -0.007 & -0.258 & -0.023 \\
\hline Mean std. dev. (\%) & 2.069 & 2.536 & 1.884 \\
\hline Max. std. dev. (\%) & 4.305 & 5.567 & 2.417 \\
\hline Min. std. dev. (\%) & 1.104 & 1.206 & 1.478 \\
\hline Mean kurtosis & 8.354 & 14.684 & 7.767 \\
\hline Max. kurtosis & 41.319 & 288.199 & 12.953 \\
\hline Min. kurtosis & 5.266 & 5.373 & 5.726 \\
\hline Mean skewness & 0.128 & -0.231 & -0.120 \\
\hline Max. skewness & 2.840 & 1.560 & 0.306 \\
\hline \multirow[t]{2}{*}{ Min. skewness } & -0.500 & -12.294 & -0.345 \\
\hline & \multicolumn{3}{|c|}{ Univariate data (equally weighted) } \\
\hline \multicolumn{4}{|l|}{ In sample } \\
\hline Mean return (\%) & 0.095 & 0.013 & 0.043 \\
\hline Max. return (\%) & 3.818 & 5.623 & 4.876 \\
\hline Min. return (\%) & -4.923 & -5.168 & -5.862 \\
\hline Std. dev. $(\%)$ & 0.857 & 1.050 & 1.075 \\
\hline Kurtosis & 4.638 & 6.051 & 4.463 \\
\hline Skewness & -0.253 & 0.004 & -0.102 \\
\hline \multicolumn{4}{|l|}{ Out of sample } \\
\hline Mean return (\%) & 0.048 & -0.022 & 0.010 \\
\hline Max. return (\%) & 9.829 & 11.805 & 9.796 \\
\hline Min. return (\%) & -9.255 & -9.925 & -9.843 \\
\hline Std. dev. $(\%)$ & 1.768 & 1.779 & 1.811 \\
\hline Kurtosis & 7.260 & 10.657 & 7.343 \\
\hline Skewness & -0.203 & -0.212 & -0.192 \\
\hline
\end{tabular}


data set) are smaller than the corresponding mean standard deviations reported in the top panel of the table, both in the in- and out-of-sample periods. The same happens for the skewness and kurtosis measures. The skewness coefficients for equally weighted portfolios are negative and larger (in size) in the out-of-sample period, and the kurtosis are also larger than 3.

For each of the data sets and using the first 1639 observations, we estimate all univariate and multivariate models by QML as explained in Section 3, but now maximizing both the Gaussian and the Student's $t$ log-likelihood functions. In the second case, we denote the model by adding a " $t$ " to the corresponding acronyms. The only exception is the GARCH-FHS approach that is based on the estimation of the GARCH model assuming Gaussian errors. ${ }^{6}$ Table 8 reports the estimated parameters of all models for each of the three portfolios considered, along with their asymptotic standard deviations computed using numerical derivatives ${ }^{7}$. The estimates have been restricted to satisfy the positivity and stationarity conditions. The parameter estimates are significant and similar to those found in previous works by other authors. For instance, the values of the DCC and AsyDCC parameters are similar to those reported in Cappiello, Engle, and Sheppard (2006), whereas the values of the CAViaR-estimated parameters are similar to those reported in Engle and Manganelli (2004). As in Engle and Sheppard (2001), we observe that the estimated news parameter, $\alpha$, in the DCC models are significant in all cases. Furthermore, the parameter $\delta$ associated to the asymmetric term in the AsyDCC model in the industry and size- $\mathrm{B} / \mathrm{M}$ portfolios is positive and significant when considering Gaussian error distributions, and the associated estimated values are close to those reported in Cappiello, Engle, and Sheppard (2006). When considering the Student's $t$ as the error distribution, we find that the asymmetry parameter in the AsyDCC model is positive and significant for the S\&P100 stocks and nearly zero and nonsignificant for the remaining instances.

For the univariate models, we find that the parameter $\delta$ associated to the asymmetric term is significant in all cases. Finally, we observe that, in general, the estimates of the degrees of freedom, $v$, in the GARCH- $t$, GJR- $t$, EGARCH- $t$, and APARCH- $t$ models are very large, suggesting that the univariate standardized returns can be adequately represented by the Gaussian distribution when these models are fitted to represent the evolution of their conditional variances. For the Industry and Size-B/M portfolios, the estimated degrees of freedom for the univariate models are larger than 45 in all specifications. For the S\&P100 data set, the estimated values are larger than 15 . For the multivariate models, however, we find that the estimated degrees of freedom are lower than 7 in all specifications

\footnotetext{
${ }^{6}$ We also consider a CCC model in which the unconditional correlation matrix of standardized returns is given by the identity matrix, which implies that all cross-correlations are assumed to be zero. Moreover, we consider the multivariate FHS procedure suggested by Christoffersen (2009). These models, however, perform very poorly in comparison to the multivariate specifications considered in this article. Consequently, we do not report the corresponding results.

${ }^{7}$ Note that we have not included parameter estimates of the multivariate CCC models because they do not present dynamics in the conditional correlations.
} 


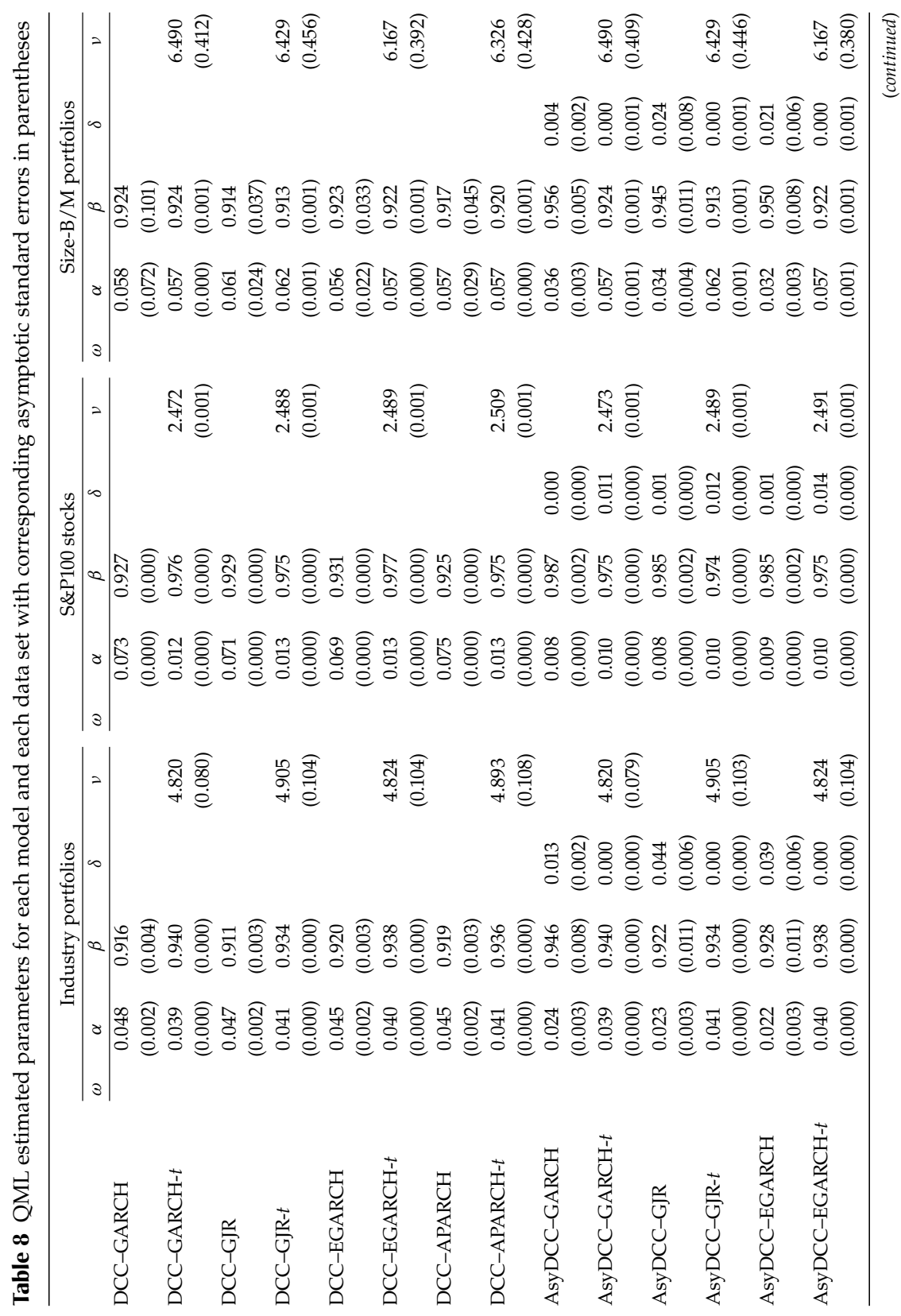




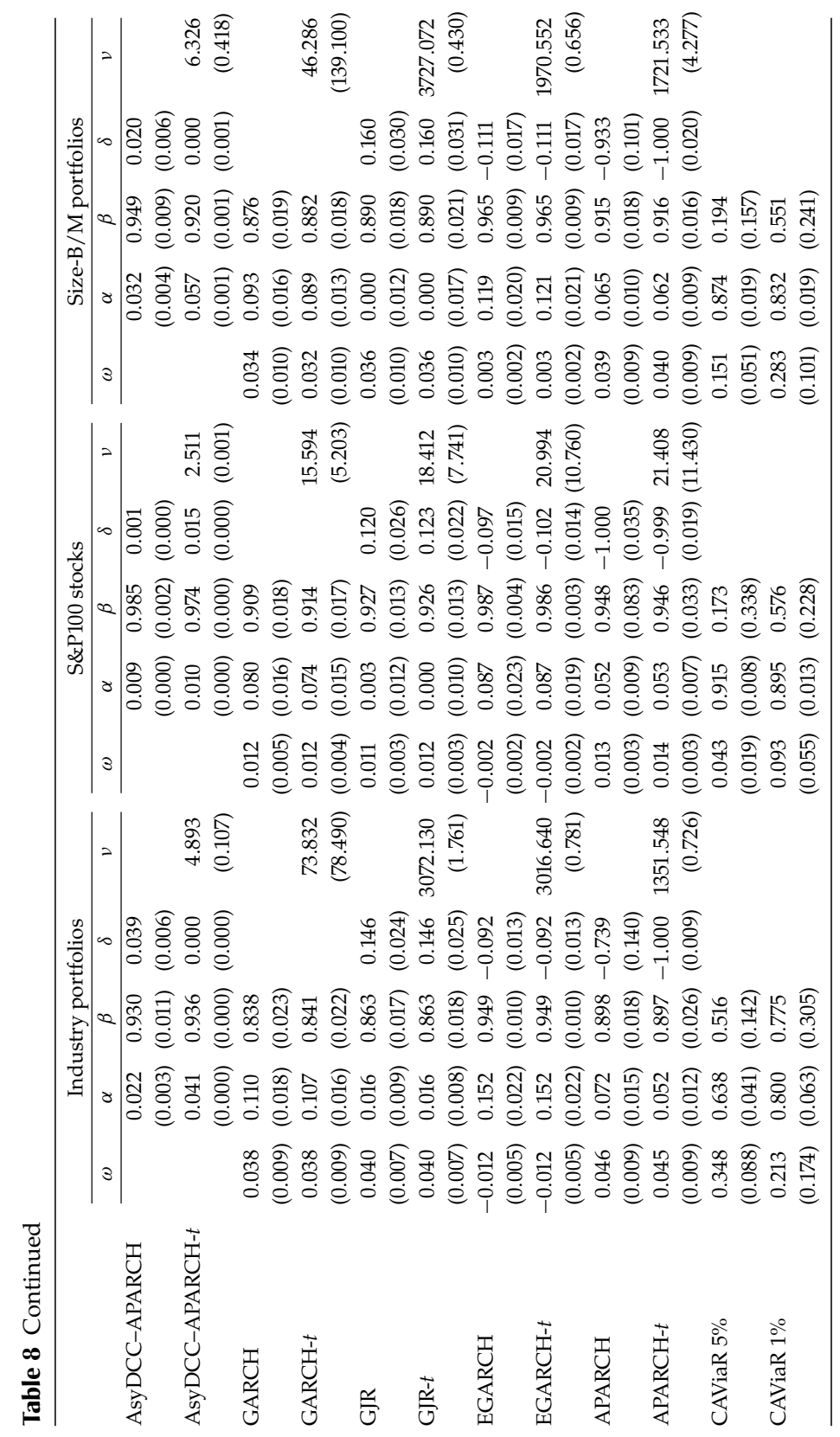


and in all data sets. These findings are consistent with those obtained by Pesaran and Pesaran (2010). Given that the parameter estimates of the univariate Gaussian and Student's $t$ models are very similar in all data sets, we focus solely on the performance of univariate Gaussian models.

After estimating the parameters, we obtain out-of-sample forecasts of the VaR using two alternative strategies. First, out-of-sample forecasts are obtained using a fixed estimation window as in the Monte Carlo simulations. In this case, the out-of-sample VaRs are computed with the parameters reported in Table 8 that are kept fixed during the out-of-sample period. The main advantage of this procedure is that it entails less computational effort since all models are estimated only once. However, parameter estimates may become outdated and possibly harm the predictive accuracy. Our second strategy is to obtain out-of-sample forecasts using rolling estimation windows of $T-1000$ observations, in which the parameters are reestimated 1000 times in order to provide one-step-ahead forecasts. Obviously, although this strategy implies a huge computational effort, the resulting out-of-sample forecasts tend to gain accuracy.

\subsection{Results using fixed estimation window}

Table 9 reports the backtesting results for the three portfolios considered based on out-of-sample $1 \%$-VaR estimates obtained with a fixed estimation window. For each portfolio, Table 9 reports the empirical coverage of each model and the $p$-values of the independence, unconditional, and conditional coverage tests, respectively. We can observe that, for the three portfolios and all VaR estimation procedures, the empirical coverages of all models tend to fall far beyond their expected nominal level of $1 \%$. This result is likely to be related to the financial crisis that started in 2007-2008 and was also found by Pesaran and Pesaran (2010). This is also confirmed in Table 7, where we observe that out-of-sample unconditional moments are different with respect to in-sample moments, with average returns becoming lower and average standard deviation becoming higher in the out-of-sample period. Following a period of calm in financial markets, the VaR estimates can decline to low levels, but they might underestimate risk during a period of stress that lies ahead, resulting in an increase in the number of violations.

We can also observe in Table 9, except for the CCC model, that multivariate Student's $t$ models deliver always a lower number of violations in comparison to their Gaussian counterparts, resulting in empirical coverages closer to the nominal levels of $1 \%$. For the industry portfolios and size-B/M portfolios, the best performance in terms of empirical coverage was achieved by the DCC-GJR-t $(2.2 \%$ and $1.5 \%$, respectively), whereas for the S\&P100 stocks the best performance was achieved by the univariate CAViaR model (2.1\%). Finally, the comparison among alternative multivariate models indicated that DCC and AsyDCC models perform better than CCC models, suggesting that, in fact, conditional correlations tend to be dynamic rather than constant. When looking at the $p$-values of the backtests, we can also 


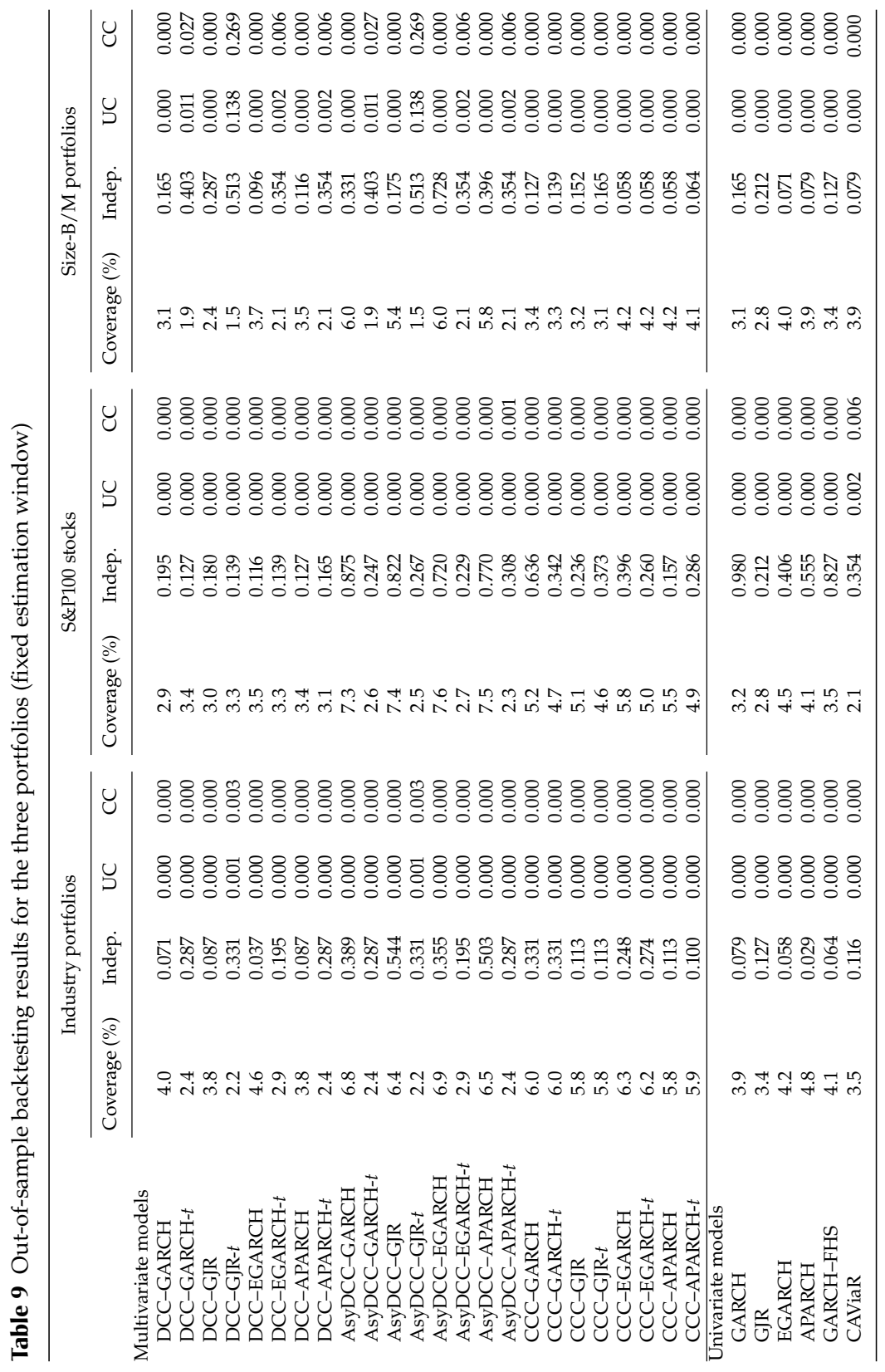


observe that in the industry portfolios and S\&P100 stocks data sets, all models reject the null hypothesis of independence and correct conditional coverage. On the other hand, the backtesting results for the size-B/M portfolios indicate that the DCC-GJR- $t$ model achieves a remarkable performance as it is the only model that passes all tests.

Tables 10-12 report the results for pairwise comparisons among all candidate models according to the CPA test for each of the three data sets considered, respectively. In these tables, after each CPA coefficient, a left (up) arrow means that the univariate model in the row outperforms (underperforms) the univariate model in the column. The associated $p$-values appear in parentheses. The results corroborates the evidence from the backtests discussed before, as they indicate that multivariate models outperform their univariate counterparts in most cases. For the industry and size-B/M portfolios, Tables 10 and 12 show that all DCC- $t$ and AsyDCC- $t$ specifications outperformed all univariate models. For the S\&P100 stocks, however, Table 11 reveals that the univariate GJR and CAViaR models outperforms all multivariate models. Finally, we observe that multivariate models with constant conditional correlations usually underperform, thus corroborating the evidence that assuming conditional correlations to be time-varying rather than constant leads to improvements in the VaR forecasts. Finally, it is important to point out that when estimating multivariate models with Gaussian errors the results are mixed.

The backtesting results obtained with fixed estimation window discussed above leave room for discussion. Even though multivariate models outperform their univariate counterparts when implemented to forecast the portfolio $1 \%$-VaR for two portfolios considered in this article, the majority of both specifications fails to pass the backtests in most of the cases. One possible explanation for this result could be the fact that the parameters estimated in the in-sample period are kept fixed in the out-of-sample period. Therefore, considering that the out-of-sample unconditional moments reported in Table 7 are very much different with respect to in-sample moments, one can suspect that the out-of-sample VaR forecasts will yield much higher empirical coverage rates and, consequently, failing to pass the backtests. In fact, the results reported in Table 9 confirm this idea. Obviously, multivariate models with Student's $t$ innovations tend to be less affected by this problem since some of the individual assets already exhibit in the in-sample period high standard deviation and kurtosis, which tends to make the estimated degrees of freedom small and consequently leads to better empirical coverage rates in the out-of-sample period.

\subsection{Results using rolling estimation window}

To circumvent the limitations imposed by the fixed estimation window, we consider an alternative estimation strategy in which parameters are reestimated using a rolling window of $T-1000$ observations. Starting from the first observation, we estimate the parameters and obtain a one-step-ahead forecast. We repeat this 
Table 10 Results of CPA test with $p$-values in parentheses

\begin{tabular}{|c|c|c|c|c|c|c|}
\hline & GARCH & GJR & EGARCH & APARCH & GARCH-FHS & CAViaR \\
\hline DCC-GARCH & $\begin{array}{c}8.718 \uparrow \\
(0.012)\end{array}$ & $\begin{array}{l}18.493 \uparrow \\
(0.000)\end{array}$ & $\begin{array}{c}7.799 \leftarrow \\
(0.020)\end{array}$ & $\begin{array}{l}12.642 \leftarrow \\
(0.001)\end{array}$ & $\begin{array}{l}12.979 \leftarrow \\
(0.001)\end{array}$ & $\begin{array}{c}9.533 \uparrow \\
(0.008)\end{array}$ \\
\hline DCC-GARCH- $t$ & $\begin{array}{l}15.393 \leftarrow \\
(0.000)\end{array}$ & $\begin{array}{l}7.031 \leftarrow \\
(0.029)\end{array}$ & $\begin{array}{l}11.120 \leftarrow \\
(0.003)\end{array}$ & $\begin{array}{l}15.369 \leftarrow \\
(0.000)\end{array}$ & $\begin{array}{l}20.872 \leftarrow \\
(0.000)\end{array}$ & $\begin{array}{l}19.737 \longleftarrow \\
(0.000)\end{array}$ \\
\hline DCC-GJR & $\begin{array}{l}15.418 \leftarrow \\
(0.000)\end{array}$ & $\begin{array}{l}8.573 \leftarrow \\
(0.013)\end{array}$ & $\begin{array}{l}11.021 \leftarrow \\
(0.004)\end{array}$ & $\begin{array}{l}17.754 \leftarrow \\
(0.000)\end{array}$ & $\begin{array}{l}25.482 \leftarrow \\
(0.000)\end{array}$ & $\begin{array}{l}7.286 \leftarrow \\
(0.026)\end{array}$ \\
\hline DCC-GJR- $t$ & $\begin{array}{l}22.339 \leftarrow \\
(0.000)\end{array}$ & $\begin{array}{l}10.663 \leftarrow \\
(0.004)\end{array}$ & $\begin{array}{l}13.999 \leftarrow \\
(0.000)\end{array}$ & $\begin{array}{l}19.223 \leftarrow \\
(0.000)\end{array}$ & $\begin{array}{c}25.942 \leftarrow \\
(0.000)\end{array}$ & $\begin{array}{l}14.560 \leftarrow \\
(0.000)\end{array}$ \\
\hline DCC-EGARCH & $\begin{array}{l}7.078 \uparrow \\
(0.029)\end{array}$ & $\begin{array}{l}13.083 \uparrow \\
(0.001)\end{array}$ & $\begin{array}{l}16.316 \leftarrow \\
(0.000)\end{array}$ & $\begin{array}{l}24.223 \leftarrow \\
(0.000)\end{array}$ & $\begin{array}{c}6.479 \uparrow \\
(0.039)\end{array}$ & $\begin{array}{c}8.302 \uparrow \\
(0.015)\end{array}$ \\
\hline DCC-EGARCH- $t$ & $\begin{array}{l}19.420 \leftarrow \\
(0.000)\end{array}$ & $\begin{array}{l}8.314 \leftarrow \\
(0.015)\end{array}$ & $\begin{array}{l}19.489 \leftarrow \\
(0.000)\end{array}$ & $\begin{array}{c}30.864 \leftarrow \\
(0.000)\end{array}$ & $\begin{array}{c}27.048 \leftarrow \\
(0.000)\end{array}$ & $\begin{array}{l}12.495 \\
(0.001)\end{array}$ \\
\hline DCC-APARCH & $\begin{array}{l}10.037 \leftarrow \\
(0.006)\end{array}$ & $\begin{array}{c}9.809 \uparrow \\
(0.007)\end{array}$ & $\begin{array}{l}10.647 \leftarrow \\
(0.004)\end{array}$ & $\begin{array}{l}18.352 \leftarrow \\
(0.000)\end{array}$ & $\begin{array}{l}17.798 \leftarrow \\
(0.000)\end{array}$ & $\begin{array}{c}7.070 \uparrow \\
(0.029)\end{array}$ \\
\hline DCC-APARCH- $t$ & $\begin{array}{l}22.350 \leftarrow \\
(0.000)\end{array}$ & $\begin{array}{l}16.532 \leftarrow \\
(0.000)\end{array}$ & $\begin{array}{l}14.313 \leftarrow \\
(0.000)\end{array}$ & $\begin{array}{l}20.280 \leftarrow \\
(0.000)\end{array}$ & $\begin{array}{l}24.375 \leftarrow \\
(0.000)\end{array}$ & $\begin{array}{l}13.138 \leftarrow \\
(0.001)\end{array}$ \\
\hline AsyDCC-GARCH & $\begin{array}{l}19.649 \uparrow \\
(0.000)\end{array}$ & $\begin{array}{c}20.810 \uparrow \\
(0.000)\end{array}$ & $\begin{array}{c}22.831 \uparrow \\
(0.000)\end{array}$ & $\begin{array}{l}19.491 \uparrow \\
(0.000)\end{array}$ & $\begin{array}{l}19.614 \uparrow \\
(0.000)\end{array}$ & $\begin{array}{c}20.209 \uparrow \\
(0.000)\end{array}$ \\
\hline AsyDCC-GARCH- $t$ & $\begin{array}{l}15.393 \leftarrow \\
(0.000)\end{array}$ & $\begin{array}{l}7.031 \leftarrow \\
(0.000)\end{array}$ & $\begin{array}{l}11.120 \leftarrow \\
(0.000)\end{array}$ & $\begin{array}{l}15.369 \leftarrow \\
(0.000)\end{array}$ & $\begin{array}{c}20.873 \leftarrow \\
(0.000)\end{array}$ & $\begin{array}{l}19.738 \leftarrow \\
(0.000)\end{array}$ \\
\hline AsyDCC-GJR & $\begin{array}{l}18.448 \uparrow \\
(0.000)\end{array}$ & $\begin{array}{c}20.175 \uparrow \\
(0.000)\end{array}$ & $\begin{array}{c}22.888 \uparrow \\
(0.000)\end{array}$ & $\begin{array}{l}18.885 \uparrow \\
(0.000)\end{array}$ & $\begin{array}{l}18.370 \uparrow \\
(0.000)\end{array}$ & $\begin{array}{l}19.066 \uparrow \\
(0.000)\end{array}$ \\
\hline AsyDCC-GJR- $t$ & $\begin{array}{l}22.339 \leftarrow \\
(0.000)\end{array}$ & $\begin{array}{l}10.663 \leftarrow \\
(0.000)\end{array}$ & $\begin{array}{l}13.999 \leftarrow \\
(0.000)\end{array}$ & $\begin{array}{l}19.223 \leftarrow \\
(0.000)\end{array}$ & $\begin{array}{c}25.942 \leftarrow \\
(0.000)\end{array}$ & $\begin{array}{l}14.560 \leftarrow \\
(0.000)\end{array}$ \\
\hline AsyDCC-EGARCH & $\begin{array}{c}20.440 \uparrow \\
(0.000)\end{array}$ & $\begin{array}{c}22.079 \uparrow \\
(0.000)\end{array}$ & $\begin{array}{c}25.151 \uparrow \\
(0.000)\end{array}$ & $\begin{array}{l}21.566 \uparrow \\
(0.000)\end{array}$ & $\begin{array}{c}20.421 \uparrow \\
(0.000)\end{array}$ & $\begin{array}{l}21.000 \uparrow \\
(0.000)\end{array}$ \\
\hline AsyDCC-EGARCH- $t$ & $\begin{array}{l}19.417 \leftarrow \\
(0.000)\end{array}$ & $\begin{array}{l}8.315 \leftarrow \\
(0.000)\end{array}$ & $\begin{array}{l}19.488 \leftarrow \\
(0.000)\end{array}$ & $\begin{array}{c}30.857 \leftarrow \\
(0.000)\end{array}$ & $\begin{array}{c}27.040 \leftarrow \\
(0.000)\end{array}$ & $\begin{array}{l}12.495 \leftarrow \\
(0.000)\end{array}$ \\
\hline AsyDCC-APARCH & $\begin{array}{l}18.700 \uparrow \\
(0.000)\end{array}$ & $\begin{array}{c}20.392 \uparrow \\
(0.000)\end{array}$ & $\begin{array}{c}23.108 \uparrow \\
(0.000)\end{array}$ & $\begin{array}{l}19.372 \uparrow \\
(0.000)\end{array}$ & $\begin{array}{l}18.616 \uparrow \\
(0.000)\end{array}$ & $\begin{array}{l}19.300 \uparrow \\
(0.000)\end{array}$ \\
\hline AsyDCC-APARCH- $t$ & $\begin{array}{l}22.351 \leftarrow \\
(0.000)\end{array}$ & $\begin{array}{l}16.532 \leftarrow \\
(0.000)\end{array}$ & $\begin{array}{l}14.313 \leftarrow \\
(0.000)\end{array}$ & $\begin{array}{c}20.280 \leftarrow \\
(0.000)\end{array}$ & $\begin{array}{c}24.375 \leftarrow \\
(0.000)\end{array}$ & $\begin{array}{l}13.138 \leftarrow \\
(0.000)\end{array}$ \\
\hline CCC-GARCH & $\begin{array}{l}17.510 \uparrow \\
(0.000)\end{array}$ & $\begin{array}{l}16.866 \uparrow \\
(0.000)\end{array}$ & $\begin{array}{l}10.161 \uparrow \\
(0.006)\end{array}$ & $\begin{array}{c}8.741 \uparrow \\
(0.012)\end{array}$ & $\begin{array}{l}17.470 \uparrow \\
(0.000)\end{array}$ & $\begin{array}{l}18.140 \uparrow \\
(0.000)\end{array}$ \\
\hline CCC-GARCH- $t$ & $\begin{array}{l}16.781 \uparrow \\
(0.000)\end{array}$ & $\begin{array}{c}15.919 \uparrow \\
(0.000)\end{array}$ & $\begin{array}{c}8.468 \uparrow \\
(0.014)\end{array}$ & $\begin{array}{c}7.390 \uparrow \\
(0.024)\end{array}$ & $\begin{array}{l}16.574 \uparrow \\
(0.000)\end{array}$ & $\begin{array}{c}17.431 \uparrow \\
(0.000)\end{array}$ \\
\hline CCC-GJR & $\begin{array}{l}13.232 \uparrow \\
(0.001)\end{array}$ & $\begin{array}{c}17.165 \uparrow \\
(0.000)\end{array}$ & $\begin{array}{l}12.088 \uparrow \\
(0.002)\end{array}$ & $\begin{array}{c}8.272 \uparrow \\
(0.015)\end{array}$ & $\begin{array}{c}12.744 \uparrow \\
(0.001)\end{array}$ & $\begin{array}{l}14.244 \uparrow \\
(0.000)\end{array}$ \\
\hline CCC-GJR- $t$ & $\begin{array}{c}12.968 \uparrow \\
(0.001)\end{array}$ & $\begin{array}{l}18.398 \uparrow \\
(0.000)\end{array}$ & $\begin{array}{l}11.868 \uparrow \\
(0.002)\end{array}$ & $\begin{array}{c}6.959 \uparrow \\
(0.030)\end{array}$ & $\begin{array}{l}12.325 \uparrow \\
(0.002)\end{array}$ & $\begin{array}{l}14.340 \uparrow \\
(0.000)\end{array}$ \\
\hline CCC-EGARCH & $\begin{array}{l}16.556 \uparrow \\
(0.000)\end{array}$ & $\begin{array}{l}18.886 \uparrow \\
(0.000)\end{array}$ & $\begin{array}{c}23.875 \uparrow \\
(0.000)\end{array}$ & $\begin{array}{l}18.293 \uparrow \\
(0.000)\end{array}$ & $\begin{array}{l}16.416 \uparrow \\
(0.000)\end{array}$ & $\begin{array}{l}17.231 \uparrow \\
(0.000)\end{array}$ \\
\hline CCC-EGARCH- $t$ & $\begin{array}{c}16.333 \uparrow \\
(0.000)\end{array}$ & $\begin{array}{l}18.767 \uparrow \\
(0.000)\end{array}$ & $\begin{array}{c}23.448 \uparrow \\
(0.000)\end{array}$ & $\begin{array}{c}17.964 \uparrow \\
(0.000)\end{array}$ & $\begin{array}{l}16.148 \uparrow \\
(0.000)\end{array}$ & $\begin{array}{c}17.013 \uparrow \\
(0.000)\end{array}$ \\
\hline CCC-APARCH & $\begin{array}{l}14.457 \uparrow \\
(0.000)\end{array}$ & $\begin{array}{l}17.433 \uparrow \\
(0.000)\end{array}$ & $\begin{array}{l}17.514 \uparrow \\
(0.000)\end{array}$ & $\begin{array}{l}13.734 \uparrow \\
(0.001)\end{array}$ & $\begin{array}{l}14.024 \uparrow \\
(0.000)\end{array}$ & $\begin{array}{l}15.222 \uparrow \\
(0.000)\end{array}$ \\
\hline CCC-APARCH- $t$ & $\begin{array}{l}15.043 \uparrow \\
(0.000)\end{array}$ & $\begin{array}{l}18.359 \uparrow \\
(0.000)\end{array}$ & $\begin{array}{l}18.517 \uparrow \\
(0.000)\end{array}$ & $\begin{array}{l}14.991 \uparrow \\
(0.000)\end{array}$ & $\begin{array}{l}14.632 \uparrow \\
(0.000)\end{array}$ & $\begin{array}{l}15.790 \uparrow \\
(0.000)\end{array}$ \\
\hline
\end{tabular}

Data set: industry portfolios. 
Table 11 Results of CPA test with $p$-values in parentheses

\begin{tabular}{|c|c|c|c|c|c|c|}
\hline & GARCH & GJR & EGARCH & APARCH & GARCH-FHS & CAViaR \\
\hline DCC-GARCH & $\begin{array}{c}7.076 \uparrow \\
(0.029)\end{array}$ & $\begin{array}{c}9.492 \uparrow \\
(0.008)\end{array}$ & $\begin{array}{l}4.734 \leftarrow \\
(0.093)\end{array}$ & $\begin{array}{l}3.235 \leftarrow \\
(0.198)\end{array}$ & $\begin{array}{c}3.723 \uparrow \\
(0.155)\end{array}$ & $\begin{array}{l}10.209 \uparrow \\
(0.006)\end{array}$ \\
\hline DCC-GARCH- $t$ & $\begin{array}{l}10.225 \uparrow \\
(0.006)\end{array}$ & $\begin{array}{l}11.717 \uparrow \\
(0.002)\end{array}$ & $\begin{array}{c}7.295 \uparrow \\
(0.026)\end{array}$ & $\begin{array}{c}4.955 \uparrow \\
(0.083)\end{array}$ & $\begin{array}{c}9.918 \uparrow \\
(0.007)\end{array}$ & $\begin{array}{l}11.420 \uparrow \\
(0.003)\end{array}$ \\
\hline DCC-GJR & $\begin{array}{l}3.267 \leftarrow \\
(0.195)\end{array}$ & $\begin{array}{l}11.138 \uparrow \\
(0.003)\end{array}$ & $\begin{array}{l}8.764 \leftarrow \\
(0.012)\end{array}$ & $\begin{array}{l}11.279 \leftarrow \\
(0.003)\end{array}$ & $\begin{array}{l}2.504 \leftarrow \\
(0.285)\end{array}$ & $\begin{array}{c}9.515 \uparrow \\
(0.008)\end{array}$ \\
\hline DCC-GJR- $t$ & $\begin{array}{l}10.082 \uparrow \\
(0.006)\end{array}$ & $\begin{array}{l}11.918 \uparrow \\
(0.002)\end{array}$ & $\begin{array}{l}6.808 \leftarrow \\
(0.033)\end{array}$ & $\begin{array}{c}2.841 \leftarrow \\
(0.241)\end{array}$ & $\begin{array}{c}9.4753 \uparrow \\
(0.008)\end{array}$ & $\begin{array}{l}11.136 \uparrow \\
(0.003)\end{array}$ \\
\hline DCC-EGARCH & $\begin{array}{c}6.880 \uparrow \\
(0.032)\end{array}$ & $\begin{array}{l}11.585 \uparrow \\
(0.003)\end{array}$ & $\begin{array}{c}2.961 \leftarrow \\
(0.227)\end{array}$ & $\begin{array}{c}0.948 \leftarrow \\
(0.622)\end{array}$ & $\begin{array}{c}5.634 \uparrow \\
(0.059)\end{array}$ & $\begin{array}{c}9.888 \uparrow \\
(0.007)\end{array}$ \\
\hline DCC-EGARCH- $t$ & $\begin{array}{c}9.202 \uparrow \\
(0.010)\end{array}$ & $\begin{array}{l}11.951 \uparrow \\
(0.002)\end{array}$ & $\begin{array}{c}8.571 \uparrow \\
(0.014)\end{array}$ & $\begin{array}{c}6.197 \uparrow \\
(0.044)\end{array}$ & & $\begin{array}{l}10.607 \uparrow \\
(0.005)\end{array}$ \\
\hline DCC-APARCH & $\begin{array}{l}8.503 \uparrow \\
(0.014)\end{array}$ & $\begin{array}{l}12.289 \uparrow \\
(0.002)\end{array}$ & $\begin{array}{c}6.477 \leftarrow \\
(0.039)\end{array}$ & $\begin{array}{l}7.200 \leftarrow \\
(0.027)\end{array}$ & $\begin{array}{l}5.232 \leftarrow \\
(0.073)\end{array}$ & $\begin{array}{l}12.147 \uparrow \\
(0.002)\end{array}$ \\
\hline DCC-APARCH- $t$ & $\begin{array}{l}9.832 \uparrow \\
(0.007)\end{array}$ & $\begin{array}{l}11.792 \uparrow \\
(0.002)\end{array}$ & $\begin{array}{l}8.676 \leftarrow \\
(0.013)\end{array}$ & $\begin{array}{l}4.291 \leftarrow \\
(0.116)\end{array}$ & $\begin{array}{l}9.434 \uparrow \\
(0.008)\end{array}$ & $\begin{array}{l}10.774 \uparrow \\
(0.004)\end{array}$ \\
\hline AsyDCC-GARCH & $\begin{array}{c}24.568 \uparrow \\
(0.000)\end{array}$ & $\begin{array}{l}24.866 \uparrow \\
(0.000)\end{array}$ & $\begin{array}{c}25.287 \uparrow \\
(0.000)\end{array}$ & $\begin{array}{c}23.681 \uparrow \\
(0.000)\end{array}$ & $\begin{array}{c}24.526 \uparrow \\
(0.000)\end{array}$ & $\begin{array}{c}25.029 \uparrow \\
(0.000)\end{array}$ \\
\hline AsyDCC-GARCH- $t$ & $\begin{array}{c}9.713 \uparrow \\
(0.007)\end{array}$ & $\begin{array}{c}9.179 \uparrow \\
(0.010)\end{array}$ & $\begin{array}{l}6.022 \leftarrow \\
(0.049)\end{array}$ & $\begin{array}{l}3.100 \leftarrow \\
(0.212)\end{array}$ & $\begin{array}{c}9.129 \uparrow \\
(0.010)\end{array}$ & $\begin{array}{l}10.104 \uparrow \\
(0.006)\end{array}$ \\
\hline AsyDCC-GJR & $\begin{array}{c}24.095 \uparrow \\
(0.000)\end{array}$ & $\begin{array}{c}24.427 \uparrow \\
(0.000)\end{array}$ & $\begin{array}{c}24.916 \uparrow \\
(0.000)\end{array}$ & $\begin{array}{c}23.245 \uparrow \\
(0.000)\end{array}$ & $\begin{array}{c}24.046 \uparrow \\
(0.000)\end{array}$ & $\begin{array}{c}24.565 \uparrow \\
(0.000)\end{array}$ \\
\hline AsyDCC-GJR- $t$ & $\begin{array}{l}10.467 \uparrow \\
(0.005)\end{array}$ & $\begin{array}{l}10.764 \uparrow \\
(0.004)\end{array}$ & $\begin{array}{l}6.714 \leftarrow \\
(0.034)\end{array}$ & $\begin{array}{l}5.088 \leftarrow \\
(0.078)\end{array}$ & $\begin{array}{l}8.537 \leftarrow \\
(0.014)\end{array}$ & $\begin{array}{l}10.858 \uparrow \\
(0.004)\end{array}$ \\
\hline AsyDCC-EGARCH & $\begin{array}{c}24.607 \uparrow \\
(0.000)\end{array}$ & $\begin{array}{l}24.935 \uparrow \\
(0.000)\end{array}$ & $\begin{array}{c}25.496 \uparrow \\
(0.000)\end{array}$ & $\begin{array}{c}23.831 \uparrow \\
(0.000)\end{array}$ & $\begin{array}{l}24.564 \uparrow \\
(0.000)\end{array}$ & $\begin{array}{c}25.061 \uparrow \\
(0.000)\end{array}$ \\
\hline AsyDCC-EGARCH- $t$ & $\begin{array}{c}8.700 \uparrow \\
(0.012)\end{array}$ & $\begin{array}{c}9.730 \uparrow \\
(0.007)\end{array}$ & $\begin{array}{l}6.655 \leftarrow \\
(0.035)\end{array}$ & $\begin{array}{l}3.599 \\
(0.165)\end{array}$ & $\begin{array}{c}8.320 \uparrow \\
(0.015)\end{array}$ & $\begin{array}{c}9.098 \uparrow \\
(0.010)\end{array}$ \\
\hline AsyDCC-APARCH & $\begin{array}{c}24.151 \uparrow \\
(0.000)\end{array}$ & $\begin{array}{c}24.492 \uparrow \\
(0.000)\end{array}$ & $\begin{array}{c}25.017 \uparrow \\
(0.000)\end{array}$ & $\begin{array}{c}23.352 \uparrow \\
(0.000)\end{array}$ & $\begin{array}{c}24.105 \uparrow \\
(0.000)\end{array}$ & $\begin{array}{c}24.614 \uparrow \\
(0.000)\end{array}$ \\
\hline AsyDCC-APARCH- $t$ & $\begin{array}{l}10.061 \uparrow \\
(0.006)\end{array}$ & $\begin{array}{l}10.170 \uparrow \\
(0.006)\end{array}$ & $\begin{array}{l}7.268 \leftarrow \\
(0.026)\end{array}$ & $\begin{array}{l}5.322 \leftarrow \\
(0.069)\end{array}$ & $\begin{array}{l}8.591 \leftarrow \\
(0.013)\end{array}$ & $\begin{array}{l}10.102 \uparrow \\
(0.006)\end{array}$ \\
\hline CCC-GARCH & $\begin{array}{l}14.641 \uparrow \\
(0.000)\end{array}$ & $\begin{array}{l}16.343 \uparrow \\
(0.000)\end{array}$ & $\begin{array}{l}12.970 \uparrow \\
(0.001)\end{array}$ & $\begin{array}{l}12.287 \uparrow \\
(0.002)\end{array}$ & $\begin{array}{l}14.276 \uparrow \\
(0.000)\end{array}$ & $\begin{array}{l}16.064 \uparrow \\
(0.000)\end{array}$ \\
\hline CCC-GARCH- $t$ & $\begin{array}{l}13.866 \uparrow \\
(0.000)\end{array}$ & $\begin{array}{c}17.073 \uparrow \\
(0.000)\end{array}$ & $\begin{array}{l}14.560 \uparrow \\
(0.000)\end{array}$ & $\begin{array}{l}14.221 \uparrow \\
(0.000)\end{array}$ & $\begin{array}{l}13.383 \uparrow \\
(0.001)\end{array}$ & $\begin{array}{l}15.375 \uparrow \\
(0.000)\end{array}$ \\
\hline CCC-GJR & $\begin{array}{l}16.557 \uparrow \\
(0.000)\end{array}$ & $\begin{array}{c}20.258 \uparrow \\
(0.000)\end{array}$ & $\begin{array}{l}19.635 \uparrow \\
(0.000)\end{array}$ & $\begin{array}{c}17.645 \uparrow \\
(0.000)\end{array}$ & $\begin{array}{l}16.103 \uparrow \\
(0.000)\end{array}$ & $\begin{array}{c}18.121 \uparrow \\
(0.000)\end{array}$ \\
\hline CCC-GJR- $t$ & $\begin{array}{l}11.827 \uparrow \\
(0.002)\end{array}$ & $\begin{array}{l}15.219 \uparrow \\
(0.000)\end{array}$ & $\begin{array}{l}13.217 \uparrow \\
(0.001)\end{array}$ & $\begin{array}{l}11.937 \uparrow \\
(0.002)\end{array}$ & $\begin{array}{l}11.290 \uparrow \\
(0.003)\end{array}$ & $\begin{array}{l}13.482 \uparrow \\
(0.001)\end{array}$ \\
\hline CCC-EGARCH & $\begin{array}{l}15.447 \uparrow \\
(0.000)\end{array}$ & $\begin{array}{l}17.660 \uparrow \\
(0.000)\end{array}$ & $\begin{array}{l}15.178 \uparrow \\
(0.000)\end{array}$ & $\begin{array}{l}14.007 \uparrow \\
(0.000)\end{array}$ & $\begin{array}{l}15.058 \uparrow \\
(0.000)\end{array}$ & $\begin{array}{l}16.950 \uparrow \\
(0.000)\end{array}$ \\
\hline CCC-EGARCH- $t$ & $\begin{array}{l}14.528 \uparrow \\
(0.000)\end{array}$ & $\begin{array}{c}17.733 \uparrow \\
(0.000)\end{array}$ & $\begin{array}{l}15.899 \uparrow \\
(0.000)\end{array}$ & $\begin{array}{l}14.947 \uparrow \\
(0.000)\end{array}$ & $\begin{array}{l}14.080 \uparrow \\
(0.000)\end{array}$ & $\begin{array}{c}15.974 \uparrow \\
(0.000)\end{array}$ \\
\hline CCC-APARCH & $\begin{array}{l}16.998 \uparrow \\
(0.000)\end{array}$ & $\begin{array}{c}20.376 \uparrow \\
(0.000)\end{array}$ & $\begin{array}{l}19.425 \uparrow \\
(0.000)\end{array}$ & $\begin{array}{l}17.950 \uparrow \\
(0.000)\end{array}$ & $\begin{array}{l}16.638 \uparrow \\
(0.000)\end{array}$ & $\begin{array}{l}18.324 \uparrow \\
(0.000)\end{array}$ \\
\hline CCC-APARCH- $t$ & $\begin{array}{l}12.365 \uparrow \\
(0.002)\end{array}$ & $\begin{array}{l}15.570 \uparrow \\
(0.000)\end{array}$ & $\begin{array}{l}13.015 \uparrow \\
(0.001)\end{array}$ & $\begin{array}{l}12.315 \uparrow \\
(0.002)\end{array}$ & $\begin{array}{l}11.879 \uparrow \\
(0.002)\end{array}$ & $\begin{array}{l}13.867 \uparrow \\
(0.000)\end{array}$ \\
\hline
\end{tabular}

Data set: S\&P100 stocks. 
Table 12 Results of CPA test with $p$-values in parentheses

\begin{tabular}{|c|c|c|c|c|c|c|}
\hline & GARCH & GJR & EGARCH & APARCH & GARCH-FHS & CAViaR \\
\hline DCC-GARCH & $\begin{array}{l}5.723 \leftarrow \\
(0.057)\end{array}$ & $\begin{array}{c}6.228 \uparrow \\
(0.044)\end{array}$ & $\begin{array}{c}5.179 \leftarrow \\
(0.075)\end{array}$ & $\begin{array}{c}9.678 \leftarrow \\
(0.007)\end{array}$ & $\begin{array}{l}11.964 \leftarrow \\
(0.002)\end{array}$ & $\begin{array}{l}12.516 \leftarrow \\
(0.001)\end{array}$ \\
\hline DCC-GARCH- $t$ & $\begin{array}{l}11.722 \leftarrow \\
(0.002)\end{array}$ & $\begin{array}{l}4.224 \leftarrow \\
(0.120)\end{array}$ & $\begin{array}{l}6.500 \leftarrow \\
(0.038)\end{array}$ & $\begin{array}{l}10.564 \leftarrow \\
(0.005)\end{array}$ & $\begin{array}{l}14.102 \leftarrow \\
(0.000)\end{array}$ & $\begin{array}{l}14.603 \leftarrow \\
(0.000)\end{array}$ \\
\hline DCC-GJR & $\begin{array}{l}7.251 \leftarrow \\
(0.026)\end{array}$ & $\begin{array}{l}2.598 \leftarrow \\
(0.272)\end{array}$ & $\begin{array}{l}7.642 \leftarrow \\
(0.021)\end{array}$ & $\begin{array}{l}14.347 \leftarrow \\
(0.000)\end{array}$ & $\begin{array}{l}12.288 \leftarrow \\
(0.002)\end{array}$ & $\begin{array}{l}16.504 \leftarrow \\
(0.000)\end{array}$ \\
\hline DCC-GJR- $t$ & $\begin{array}{l}12.671 \leftarrow \\
(0.001)\end{array}$ & $\begin{array}{l}7.252 \leftarrow \\
(0.026)\end{array}$ & $\begin{array}{l}8.4363 \leftarrow \\
(0.014)\end{array}$ & $\begin{array}{l}13.567 \leftarrow \\
(0.001)\end{array}$ & $\begin{array}{l}16.313 \leftarrow \\
(0.000)\end{array}$ & $\begin{array}{l}17.993 \leftarrow \\
(0.000)\end{array}$ \\
\hline DCC-EGARCH & $\begin{array}{c}5.157 \uparrow \\
(0.075)\end{array}$ & $\begin{array}{c}8.637 \uparrow \\
(0.013)\end{array}$ & $\begin{array}{l}7.993 \leftarrow \\
(0.018)\end{array}$ & $\begin{array}{l}25.131 \leftarrow \\
(0.000)\end{array}$ & $\begin{array}{c}9.276 \uparrow \\
(0.009)\end{array}$ & $\begin{array}{l}18.232 \leftarrow \\
(0.000)\end{array}$ \\
\hline DCC-EGARCH- $t$ & $\begin{array}{l}15.813 \leftarrow \\
(0.000)\end{array}$ & $\begin{array}{l}4.825 \leftarrow \\
(0.089)\end{array}$ & $\begin{array}{l}13.768 \leftarrow \\
(0.000)\end{array}$ & $\begin{array}{c}30.931 \leftarrow \\
(0.000)\end{array}$ & $\begin{array}{l}22.797 \leftarrow \\
(0.000)\end{array}$ & $\begin{array}{l}21.516 \leftarrow \\
(0.000)\end{array}$ \\
\hline DCC-APARCH & $\begin{array}{c}9.067 \uparrow \\
(0.010)\end{array}$ & $\begin{array}{c}8.809 \uparrow \\
(0.012)\end{array}$ & $\begin{array}{l}5.132 \leftarrow \\
(0.076)\end{array}$ & $\begin{array}{l}14.018 \leftarrow \\
(0.000)\end{array}$ & $\begin{array}{l}16.299 \leftarrow \\
(0.000)\end{array}$ & $\begin{array}{l}17.414 \leftarrow \\
(0.000)\end{array}$ \\
\hline DCC-APARCH- $t$ & $\begin{array}{l}11.345 \leftarrow \\
(0.003)\end{array}$ & $\begin{array}{c}4.737 \leftarrow \\
(0.093)\end{array}$ & $\begin{array}{c}8.614 \leftarrow \\
(0.013)\end{array}$ & $\begin{array}{l}16.141 \leftarrow \\
(0.000)\end{array}$ & $\begin{array}{l}14.508 \leftarrow \\
(0.000)\end{array}$ & $\begin{array}{l}16.442 \\
(0.000)\end{array}$ \\
\hline AsyDCC-GARCH & $\begin{array}{l}15.948 \uparrow \\
(0.000)\end{array}$ & $\begin{array}{l}15.993 \uparrow \\
(0.000)\end{array}$ & $\begin{array}{l}16.060 \uparrow \\
(0.000)\end{array}$ & $\begin{array}{l}13.757 \uparrow \\
(0.001)\end{array}$ & $\begin{array}{l}15.4 \\
(0.0\end{array}$ & $\begin{array}{l}14.134 \uparrow \\
(0.000)\end{array}$ \\
\hline AsyDCC-GARCH- $t$ & $\begin{array}{l}11.722 \leftarrow \\
(0.002)\end{array}$ & $\begin{array}{l}4.220 \leftarrow \\
(0.120)\end{array}$ & $\begin{array}{c}6.500 \leftarrow \\
(0.038)\end{array}$ & $\begin{array}{l}10.564 \leftarrow \\
(0.005)\end{array}$ & $\begin{array}{l}14.102 \leftarrow \\
(0.000)\end{array}$ & $\begin{array}{l}14.603 \leftarrow \\
(0.000)\end{array}$ \\
\hline AsyDCC-GJR & $\begin{array}{l}14.922 \uparrow \\
(0.000)\end{array}$ & $\begin{array}{l}15.389 \uparrow \\
(0.000)\end{array}$ & $\begin{array}{l}15.793 \uparrow \\
(0.000)\end{array}$ & $\begin{array}{l}13.218 \uparrow \\
(0.001)\end{array}$ & $\begin{array}{l}14.326 \uparrow \\
(0.000)\end{array}$ & $\begin{array}{l}12.941 \uparrow \\
(0.001)\end{array}$ \\
\hline AsyDCC-GJR- $t$ & $\begin{array}{l}12.671 \leftarrow \\
(0.001)\end{array}$ & $\begin{array}{c}7.257 \leftarrow \\
(0.026)\end{array}$ & $\begin{array}{l}8.436 \leftarrow \\
(0.014)\end{array}$ & $\begin{array}{l}13.567 \leftarrow \\
(0.001)\end{array}$ & $\begin{array}{l}16.313 \leftarrow \\
(0.000)\end{array}$ & $\begin{array}{l}17.993 \\
(0.000)\end{array}$ \\
\hline AsyDCC-EGARCH & $\begin{array}{l}17.448 \uparrow \\
(0.000)\end{array}$ & $\begin{array}{l}17.893 \uparrow \\
(0.000)\end{array}$ & $\begin{array}{l}19.086 \uparrow \\
(0.000)\end{array}$ & $\begin{array}{l}16.666 \uparrow \\
(0.000)\end{array}$ & $\begin{array}{l}16.987 \uparrow \\
(0.000)\end{array}$ & $\begin{array}{l}15.851 \uparrow \\
(0.000)\end{array}$ \\
\hline AsyDCC-EGARCH- $t$ & $\begin{array}{l}15.828 \leftarrow \\
(0.000)\end{array}$ & $\begin{array}{l}4.836 \leftarrow \\
(0.089)\end{array}$ & $\begin{array}{l}13.838 \leftarrow \\
(0.000)\end{array}$ & $\begin{array}{l}31.029 \leftarrow \\
(0.000)\end{array}$ & $\begin{array}{l}22.789 \leftarrow \\
(0.000)\end{array}$ & $\begin{array}{l}21.548 \\
(0.000)\end{array}$ \\
\hline AsyDCC-APARCH & $\begin{array}{l}16.893 \uparrow \\
(0.000)\end{array}$ & $\begin{array}{l}17.318 \uparrow \\
(0.000)\end{array}$ & $\begin{array}{l}18.429 \uparrow \\
(0.000)\end{array}$ & $\begin{array}{l}16.004 \uparrow \\
(0.000)\end{array}$ & $\begin{array}{l}16.420 \uparrow \\
(0.000)\end{array}$ & $\begin{array}{l}15.214 \uparrow \\
(0.000)\end{array}$ \\
\hline AsyDCC-APARCH- $t$ & $\begin{array}{l}11.345 \leftarrow \\
(0.003)\end{array}$ & $\begin{array}{c}4.738 \leftarrow \\
(0.093)\end{array}$ & $\begin{array}{l}8.614 \leftarrow \\
(0.013)\end{array}$ & $\begin{array}{l}16.141 \leftarrow \\
(0.000)\end{array}$ & $\begin{array}{l}14.508 \leftarrow \\
(0.000)\end{array}$ & $\begin{array}{l}16.442 \\
(0.000)\end{array}$ \\
\hline CCC-GARCH & $\begin{array}{l}12.715 \uparrow \\
(0.001)\end{array}$ & $\begin{array}{l}11.717 \uparrow \\
(0.002)\end{array}$ & $\begin{array}{l}7.550 \leftarrow \\
(0.022)\end{array}$ & $\begin{array}{l}13.762 \leftarrow \\
(0.001)\end{array}$ & $\begin{array}{l}12.531 \uparrow \\
(0.001)\end{array}$ & $\begin{array}{c}7.448 \leftarrow \\
(0.024)\end{array}$ \\
\hline CCC-GARCH- $t$ & $\begin{array}{l}12.090 \uparrow \\
(0.002)\end{array}$ & $\begin{array}{l}10.952 \uparrow \\
(0.004)\end{array}$ & $\begin{array}{c}7.311 \leftarrow \\
(0.025)\end{array}$ & $\begin{array}{l}13.244 \leftarrow \\
(0.001)\end{array}$ & $\begin{array}{l}12.066 \leftarrow \\
(0.002)\end{array}$ & $\begin{array}{l}7.139 \leftarrow \\
(0.028)\end{array}$ \\
\hline CCC-GJR & $\begin{array}{c}6.839 \uparrow \\
(0.032)\end{array}$ & $\begin{array}{l}11.333 \uparrow \\
(0.003)\end{array}$ & $\begin{array}{l}6.989 \leftarrow \\
(0.030)\end{array}$ & $\begin{array}{l}15.946 \leftarrow \\
(0.000)\end{array}$ & $\begin{array}{l}9.011 \leftarrow \\
(0.011)\end{array}$ & $\begin{array}{l}12.622 \\
(0.001)\end{array}$ \\
\hline CCC-GJR- $t$ & $\begin{array}{c}7.307 \uparrow \\
(0.025)\end{array}$ & $\begin{array}{l}10.851 \uparrow \\
(0.004)\end{array}$ & $\begin{array}{l}6.956 \leftarrow \\
(0.030)\end{array}$ & $\begin{array}{l}15.855 \leftarrow \\
(0.000)\end{array}$ & $\begin{array}{l}9.285 \leftarrow \\
(0.009)\end{array}$ & $\begin{array}{l}12.469 \leftarrow \\
(0.001)\end{array}$ \\
\hline CCC-EGARCH & $\begin{array}{c}8.006 \uparrow \\
(0.018)\end{array}$ & $\begin{array}{l}13.717 \uparrow \\
(0.001)\end{array}$ & $\begin{array}{l}11.847 \uparrow \\
(0.002)\end{array}$ & $\begin{array}{l}10.273 \uparrow \\
(0.005)\end{array}$ & $\begin{array}{c}7.128 \uparrow \\
(0.028)\end{array}$ & $\begin{array}{c}9.194 \uparrow \\
(0.010)\end{array}$ \\
\hline CCC-EGARCH- $t$ & $\begin{array}{c}7.999 \uparrow \\
(0.018)\end{array}$ & $\begin{array}{l}13.711 \uparrow \\
(0.001)\end{array}$ & $\begin{array}{l}11.897 \uparrow \\
(0.002)\end{array}$ & $\begin{array}{l}10.143 \uparrow \\
(0.006)\end{array}$ & $\begin{array}{c}7.165 \uparrow \\
(0.027)\end{array}$ & $\begin{array}{c}9.468 \uparrow \\
(0.008)\end{array}$ \\
\hline CCC-APARCH & $\begin{array}{c}9.948 \uparrow \\
(0.006)\end{array}$ & $\begin{array}{l}16.996 \uparrow \\
(0.000)\end{array}$ & $\begin{array}{c}9.110 \leftarrow \\
(0.010)\end{array}$ & $\begin{array}{l}17.300 \leftarrow \\
(0.000)\end{array}$ & $\begin{array}{l}11.658 \uparrow \\
(0.002)\end{array}$ & $\begin{array}{c}20.573 \uparrow \\
(0.000)\end{array}$ \\
\hline CCC-APARCH- $t$ & $\begin{array}{c}9.933 \uparrow \\
(0.006)\end{array}$ & $\begin{array}{l}16.822 \uparrow \\
(0.000)\end{array}$ & $\begin{array}{l}8.057 \leftarrow \\
(0.017)\end{array}$ & $\begin{array}{l}16.967 \leftarrow \\
(0.000)\end{array}$ & $\begin{array}{l}12.429 \uparrow \\
(0.001)\end{array}$ & $\begin{array}{c}22.023 \leftarrow \\
(0.000)\end{array}$ \\
\hline
\end{tabular}

Data set: size and book-to-market portfolios. 
Table 13 Out-of-sample backtesting results for the three portfolios (rolling estimation window)

\begin{tabular}{lcccc}
\hline & \multicolumn{4}{c}{ Industry portfolios } \\
\cline { 2 - 5 } & Coverage (\%) & Indep. & UC & CC \\
\cline { 2 - 5 } DCC-GJR- $t$ & 1.8 & 0.429 & 0.022 & 0.053 \\
AsyDCC-GJR- $t$ & 1.8 & 0.429 & 0.022 & 0.053 \\
GJR & 3.2 & 0.152 & 0.000 & 0.000 \\
CAViaR & 2.4 & 0.287 & 0.000 & 0.000 \\
\cline { 2 - 5 } & \multicolumn{5}{c}{ S\&P100 stocks } \\
DCC-GJR-t & 2.4 & 0.287 & 0.000 \\
AsyDCC-GJR- $t$ & 1.9 & 0.403 & 0.011 & 0.000 \\
GJR & 3.2 & 0.152 & 0.000 & 0.000 \\
CAViaR & 1.7 & 0.456 & 0.043 & 0.097 \\
\cline { 2 - 5 } & 1.2 & Size-B/M portfolios \\
DCC-GJR- $t$ & 1.2 & 0.605 & 0.722 \\
AsyDCC-GJR- $t$ & 2.6 & 0.605 & 0.536 & 0.722 \\
GJR & 2.9 & 0.247 & 0.000 & 0.000 \\
CAViaR & \multicolumn{5}{c}{0.195} & 0.000 & 0.000 \\
\hline
\end{tabular}

process by discarding the oldest observation and including a new observation until the end of the sample is reached. In the end, we have a series of 1000 one-step-ahead out-of-sample forecasts. Note that this estimation strategy is very computationally demanding as each model has to be reestimated 1000 times in each of the data sets. Therefore, in order to alleviate the burden of the estimation process, we consider a subset of the multivariate and univariate models considered above. In particular, we pick the two best multivariate and the two best univariate models based on the results reported in Tables 9-12; namely the DCC-GJR-t, AsyDCC-GJR-t, GJR, and CAViaR models.

Table 13 reports the backtesting results for these four models and for the three portfolios considered in this article. As expected, the results are better in comparison to those obtained with a fixed estimation window. We can observe that all models deliver empirical coverage rates closer to the expected nominal level. For instance, the DCC-GJR- $t$ model delivered an empirical coverage of $1.8 \%$ in the case of the industry portfolios, whereas the same figure in Table 9 is $2.2 \%$. The same figures for the CAViaR model are $2.4 \%$ and $3.5 \%$, respectively. More importantly, we find that in two data sets (industry portfolios and size-B/M portfolios) multivariate models deliver empirical coverage rates closer to the nominal level in comparison to the univariate models. Moreover, for these two data sets the two multivariate models pass all backtests, while the two univariate models fail to pass them. In the case of the SP\&P100 stocks, we can observe that the AsyDCC-GJR- $t$ and CAViaR models deliver similar coverage rates (1.9\% and $1.7 \%$, respectively). 
Table 14 Model chosen according to the CPA test using a rolling estimation window

\begin{tabular}{lccc}
\hline & Industry portfolios & S\&P100 stocks & Size-B/M portfolios \\
\cline { 2 - 4 } Multivariate vs. univariate & & & \\
DCC-GJR- $t$ vs. GJR & DCC-GJR- $t^{* *}$ & DCC-GJR- $t^{*}$ & DCC-GJR- $t^{* *}$ \\
DCC-GJR- $t$ vs. CAViaR & DCC-GJR- $t^{* *}$ & CAViaR & DCC-GJR- $t^{* *}$ \\
AsyDCC-GJR- $t$ vs. GJR & AsyDCC-GJR- $t^{* *}$ & AsyDCC-GJR- $t^{* *}$ & AsyDCC-GJR- $t^{* *}$ \\
AsyDCC-GJR- $t$ vs. CAViaR & AsyDCC-GJR- $t^{* *}$ & AsyDCC-GJR- $t$ & AsyDCC-GJR- $t^{* *}$ \\
$\begin{array}{c}\text { Multivariate vs. multivariate } \\
\text { DCC-GJR- } t \text { vs. AsyDCC-GJR- } t\end{array}$ & AsyDCC-GJR- $t$ & AsyDCC-GJR- $t^{* * *}$ & DCC-GJR- $t^{*}$ \\
$\begin{array}{c}\text { Univariate vs. univariate } \\
\text { GJR vs. CAViaR }\end{array}$ & CAViaR & CAViaR & GJR \\
\hline
\end{tabular}

***Significant at $1 \%{ }^{* *}$ Significant at $5 \% *$ Significant at $10 \%$

Finally, Table 14 reports the results for pairwise comparisons among the models considered in the rolling window exercise according to the CPA test for each of the three data sets considered. These results corroborate the previous backtesting results in Table 13 and shows that multivariate models are strictly preferred to univariate models in the case of the industry and size-B/M portfolios. For the S\&P100 stocks, we observe that the CAViaR model outperforms the DCC-GJR- $t$ model. In comparison to the AsyDCC-GJR- $t$ model, however, the CAViaR model underperforms, but the difference in performance between these two models is not statistically significant. Among the multivariate models, the best models are either the AsyDCC-GJR-t or the DCC-GJR-t (not a clear preference between them). A similar finding arises when comparing the two univariate models.

Therefore, we can summarize the empirical results by noting that multivariate models tend to outperform univariate ones when forecasting one day-ahead portfolio $1 \%-\mathrm{VaR}$ for the three large and diversified portfolios considered in this article. The results are even more favorable when the VaR forecasts are obtained with rolling estimation windows. In this case, we find the the empirical coverage rates delivered by the multivariate models are closer to the expected level. Moreover, in most situations multivariate models managed to pass all backtesting tests while univariate models did not. These results are confirmed by the CPA test, which shows that multivariate models with Student's $t$ innovations tend to be the most appropriate specification for the problem of portfolio VaR forecasting.

\subsection{Robustness Check: is the 2007-2008 Financial Crisis Driving the Results?}

One possible concern to the results reported in Sections 3.1 and 3.2 is that they can be affected by the financial turmoil of 2007-2008. During this period, losses in 
Table 15 Descriptive statistics for the two out-of-sample subperiods

\begin{tabular}{|c|c|c|c|c|c|c|}
\hline & \multicolumn{2}{|c|}{ Industry portfolios } & \multicolumn{2}{|c|}{ S\&P100 stocks } & \multicolumn{2}{|c|}{ Size-B/M portfolios } \\
\hline & & 2nd & 1 st & 2nd & $1 \mathrm{st}$ & 2nd \\
\hline & subperiod & subperiod & subperio & subperiod & subperio & subperiod \\
\hline N. of observations & 500 & 500 & 500 & 500 & 500 & 500 \\
\hline Mean return (\%) & -0.006 & 0.102 & 0.001 & -0.045 & -0.001 & 0.022 \\
\hline Max. mean return (\%) & 0.172 & 0.191 & 0.196 & 0.163 & 0.038 & 0.082 \\
\hline Min. mean return (\%) & -0.114 & -0.024 & -0.221 & -0.295 & -0.035 & -0.021 \\
\hline Mean std. dev. (\%) & 1.262 & 2.635 & 1.616 & 3.183 & 1.105 & 2.422 \\
\hline Max. std. dev. (\%) & 2.515 & 5.547 & 2.825 & 7.557 & 1.295 & 3.184 \\
\hline Min. std. dev. (\%) & 0.727 & 1.383 & 0.752 & 1.531 & 0.939 & 1.868 \\
\hline Mean kurtosis & 4.600 & 6.053 & 7.714 & 10.582 & 3.967 & 5.548 \\
\hline Max. kurtosis & 20.838 & 29.910 & 32.324 & 169.336 & 5.783 & 9.911 \\
\hline Min. kurtosis & 2.946 & 4.064 & 3.136 & 4.669 & 3.443 & 3.808 \\
\hline Mean skewness & -0.152 & 0.089 & -0.291 & -0.126 & -0.155 & -0.109 \\
\hline Max. skewness & 0.401 & 2.573 & 0.842 & 1.312 & 0.093 & 0.347 \\
\hline Min. skewness & -0.942 & -0.426 & -2.371 & -9.795 & -0.427 & -0.294 \\
\hline
\end{tabular}

most banks' trading books have been substantially larger than the VaR estimates based on internal models. Therefore, in order to evaluate the impact of stressed market conditions on the performance of multivariate and univariate VaR models, we split the out-of-sample period into two subperiods with 500 observations each: from July 12, 2006 to June 23, 2008, and from June 24, 2008 to June 30, 2010. Table 15 reports the average sample moments across assets in each of the two subperiods and shows that the 2007-2008 financial crisis tends to be mostly concentrated in the second subperiod, since this period is substantially more volatile and has larger excess kurtosis than the first subperiod.

Tables 16 and 17 report the backtesting results for the multivariate and univariate models considered in Section 3.2 in each of the two subperiods considering a fixed and a rolling estimation strategy, respectively. The results corroborate our previous findings as they indicate that multivariate models outperform their univariate counterparts in the majority of the cases. Moreover, the use of a rolling estimation window usually results in empirical coverages closer to the expected nominal level of $1 \%$. During the less volatile period, Table 17 shows that the AsyDCC-GJR-t model passed the conditional coverage backtest in the three data sets. As for the univariate models, we find that both models failed to pass the backtests for the industry portfolios. Nevertheless, the CAViaR and GJR models passed the backtests for the S\&P100 stocks and the size-B/M portfolios, respectively. During the more volatile period, the CAViaR model passed the backtests only in the case of the S\&P100 stocks. On the other hand, we find that the AsyDCCGJR- $t$ model also passed the conditional coverage backtest in all the data sets. This result 


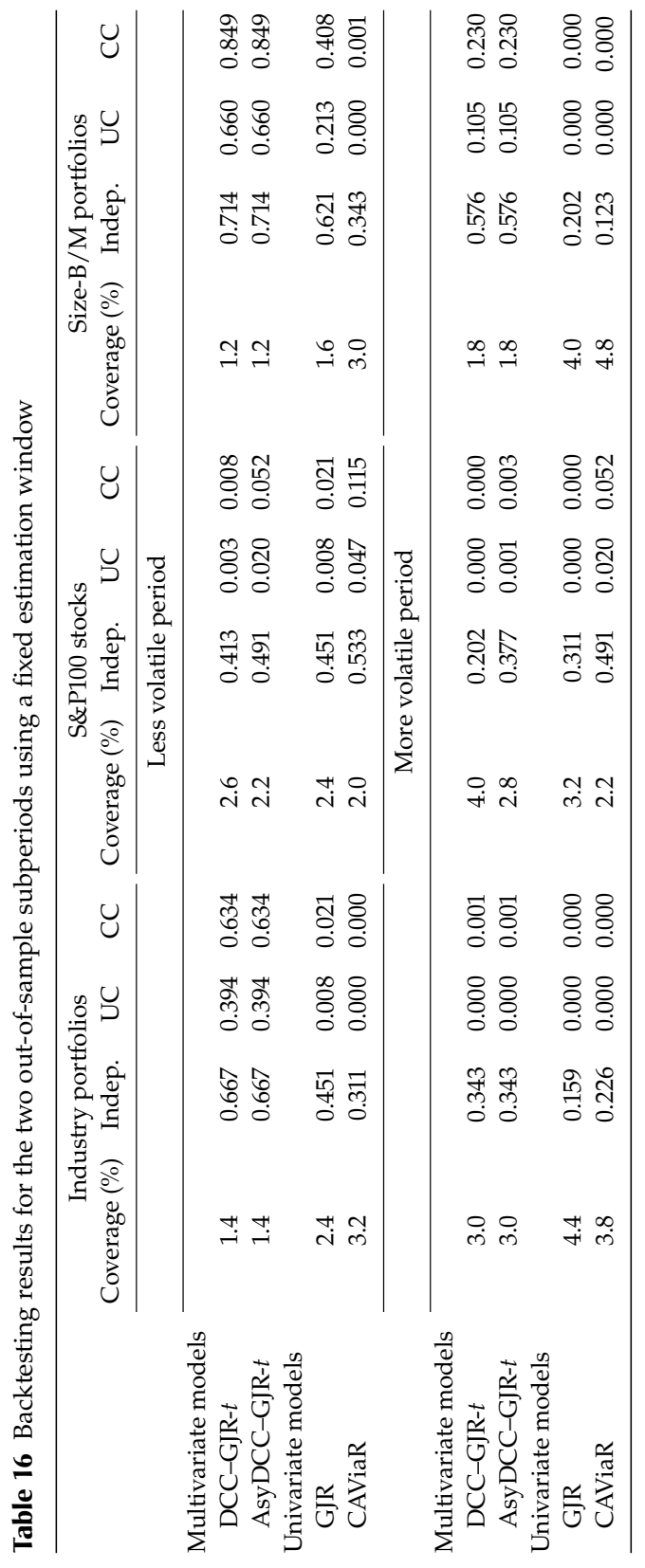




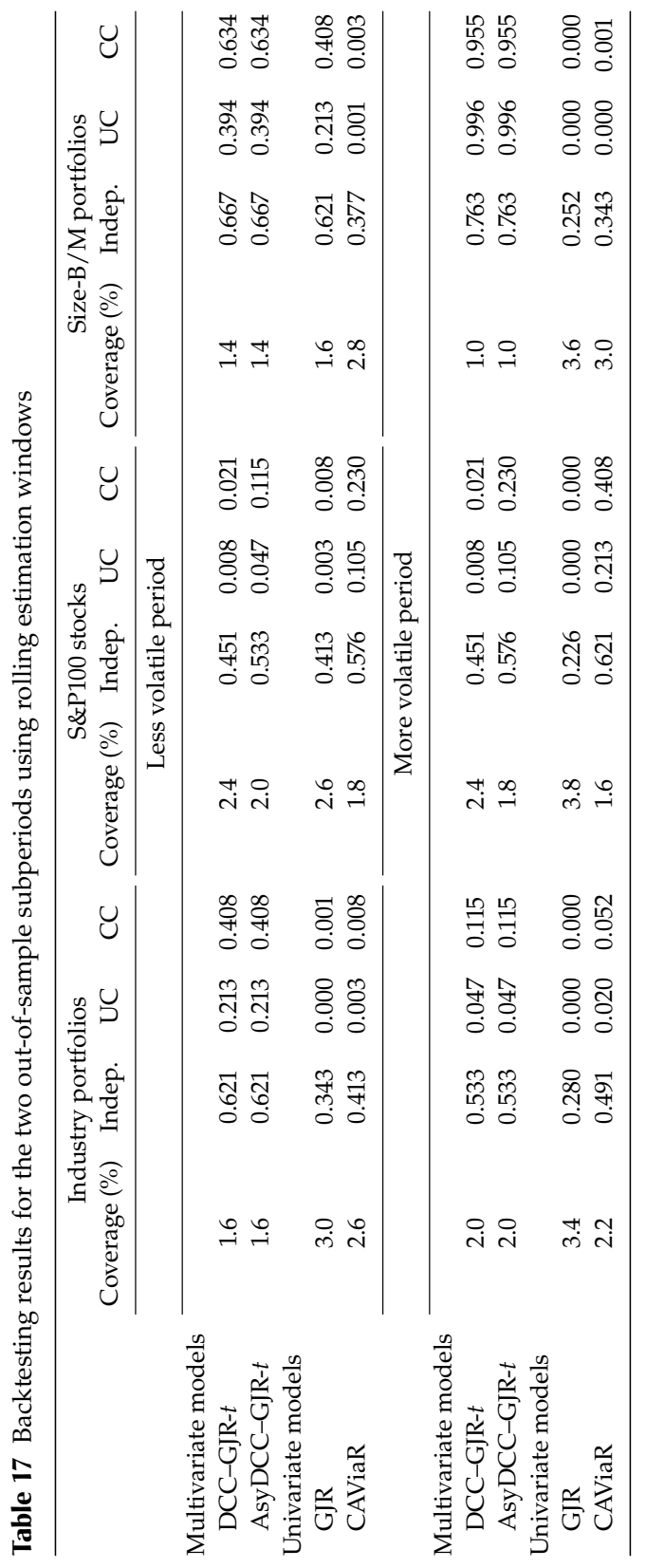


suggests that the multivariate specification can yield accurate VaR estimates even in times of high volatility such as during the 2007-2008 financial crisis.

\section{CONCLUSIONS}

Obtaining accurate risk measures can be seen as an important issue in risk management. This article addresses the question of whether multivariate or univariate models are most appropriate for the problem of portfolio VaR forecasting. We compare both types of models in the context of large and diversified portfolios, considering complex dynamics of variances and covariances with asymmetries and dynamic correlations and using both simulated and real data. The models are compared by implementing not only backtesting tests but also the CPA test that helps ranking the models according to their performance to forecast the one-step-ahead VaR. The results of the comparative predictive performance obtained in this article indicate that, although in some cases there exists no preference between univariate and multivariate models, when this preference exists it is in favor of multivariate models. This preference is clearer on an out-of-sample basis and when Student's $t$ innovations are considered.

The findings of this article have several important implications from both academic and practitioner points of view. Unlike previous empirical evidence, the results suggest that when large portfolios are considered there may exist differences in modeling multivariate and univariate conditional variances. When the objective is to measure and to forecast the VaR associated to a linear combination of the individual assets in the portfolio, it could be worth modeling the joint dynamics of those assets by fitting a multivariate model. Moreover, considering that any underestimation in the risk of a portfolio can have tremendous effects for a financial institution and for the aggregated financial system, our results show that the difference in performance with respect to univariate models is not only statistically but also economically significant. Finally, the results suggest that assuming conditional correlations to be time-varying rather than constant and exhibiting asymmetric effects can lead to VaR forecast improvements.

\section{APPENDIX: PARAMETRIZATION OF THE DATA-GENERATING PROCESSES USED TO SIMULATE DATA FOR THE MONTE CARLO EXPERIMENTS}

The O-GARCH model implemented to generate systems of $N=10$ returns specifies the conditional covariance matrix as follows

$$
\begin{aligned}
& Y_{t}=H_{t}^{1 / 2} \epsilon_{t} \\
& H_{t}=V^{1 / 2} V_{t} V^{1 / 2}
\end{aligned}
$$


where $\epsilon_{t}$ is a multivariate Gaussian white noise process with covariance matrix $\Psi$ given by

$$
\Psi=\left(\begin{array}{cccccccccc}
1.000 & 0 & & & & & & & \\
-0.099 & 1.000 & & & & & & & \\
-0.052 & 0.213 & 1.000 & & & & & & \\
-0.122 & -0.131 & -0.124 & 1.000 & & & & & \\
-0.184 & -0.221 & 0.041 & -0.221 & 1.000 & & & & \\
0.026 & 0.195 & 0.059 & 0.026 & -0.088 & 1.000 & & & \\
0.070 & -0.067 & 0.018 & 0.062 & 0.232 & 0.173 & 1.000 & & \\
-0.039 & -0.084 & -0.036 & 0.257 & -0.059 & -0.162 & 0.268 & 1.000 & \\
0.089 & -0.299 & -0.086 & 0.063 & 0.030 & -0.085 & -0.031 & -0.090 & 1.000 \\
-0.010 & -0.347 & -0.091 & 0.172 & 0.085 & 0.012 & 0.117 & 0.067 & 0.244 & 1.000
\end{array}\right)
$$

and

$$
\begin{aligned}
& V^{-1 / 2} \epsilon_{t}=\Lambda f_{t}, \\
& V_{t}=\Lambda \Sigma_{t} \Lambda^{\prime} \\
& \Sigma_{t}=\operatorname{diag}\left(h_{1, t}^{2}, h_{2, t}^{2}, h_{3, t}^{2}\right) \\
& h_{1, t}^{2}=0.01+0.10 f_{1, t-1}^{2}+0.85 h_{1, t-1}^{2}+0.05 I\left(f_{1, t-1}<0\right) f_{1, t-1}^{2} \\
& h_{2, t}^{2}=0.01+0.17 f_{2, t-1}^{2}+0.80 h_{2, t-1}^{2}+0.02 I\left(f_{2, t-1}<0\right) f_{2, t-1}^{2} \\
& h_{3, t}^{2}=0.01+0.05 f_{3, t-1}^{2}+0.90 h_{3, t-1}^{2}+0.07 I\left(f_{3, t-1}<0\right) f_{3, t-1}^{2} \\
& \Lambda=P \operatorname{diag}\left(l_{1}^{1 / 2} l_{2}^{1 / 2} l_{3}^{1 / 2}\right)
\end{aligned}
$$

where $V=\operatorname{diag}\left(v_{1}, v_{2}, \ldots, v_{N}\right)$, with $v_{i}$ being the marginal variance of $\varepsilon_{i t}, l_{1} \geq l_{2} \geq l_{3} \geq 0$ being the three largest eigenvalues of the population correlation matrix of $V^{-1 / 2} \epsilon_{t}$. Finally, $P$ is the $N \times 3$ matrix of associated mutually orthogonal eigenvectors.

The MARSV model considered as the second DGP is given by:

$$
\begin{aligned}
H_{t} & =C+A \odot H_{t-1}+\Xi_{t} \\
\Xi_{t} & \sim \operatorname{Wish}(v, \Lambda)
\end{aligned}
$$

where $C$ and $A$ are squared parameter matrices given by

$$
C=\left(\begin{array}{cccccccccc}
1.000 & & & & & & & & & \\
-0.099 & 1.000 & & & & & & & \\
-0.052 & 0.213 & 1.000 & & & & & & \\
-0.122 & -0.131 & -0.124 & 1.000 & & & & & \\
-0.184 & -0.221 & 0.041 & -0.221 & 1.000 & & & & \\
0.026 & 0.195 & 0.059 & 0.026 & -0.088 & 1.000 & & & \\
0.070 & -0.067 & 0.018 & 0.062 & 0.232 & 0.173 & 1.000 & & \\
-0.039 & -0.084 & -0.036 & 0.257 & -0.059 & -0.162 & 0.268 & 1.000 & \\
0.089 & -0.299 & -0.086 & 0.063 & 0.030 & -0.085 & -0.031 & -0.090 & 1.000 \\
-0.010 & -0.347 & -0.091 & 0.172 & 0.085 & 0.012 & 0.117 & 0.067 & 0.244 & 1.000
\end{array}\right)
$$




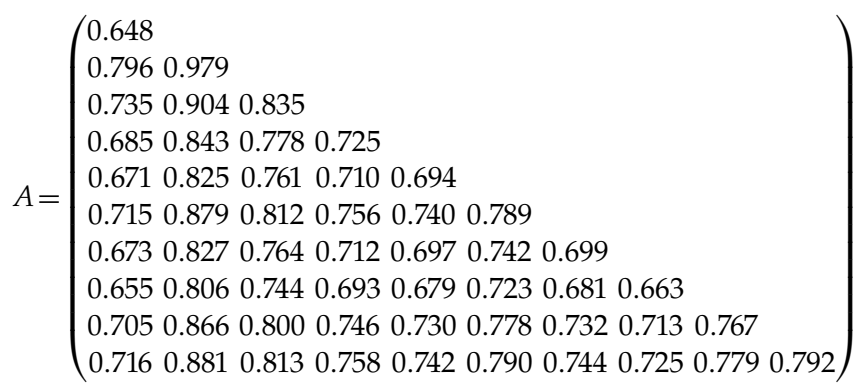

and $\Xi_{t}$ is a random matrix drawn from a Wishart distribution Wish $(v, \Lambda)$ with $v=10$ degrees of freedom and the following positive-definite scale matrix

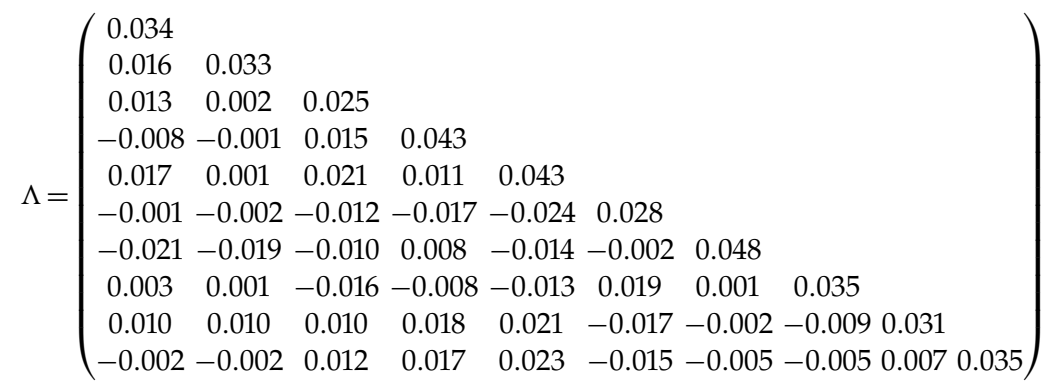

The last DGP considered is given by the following ASYDVEC model:

$$
H_{t}=C+A \odot Y_{t-1} Y_{t-1}^{\prime}+B \odot H_{t-1}+G \odot \eta_{t-1} \eta_{t-1}^{\prime}
$$

where $A, B$, and $G$ are positive-definite matrices given by

$$
A=\left(\begin{array}{llllllllll}
0.141 & & & & & & & \\
0.147 & 0.203 & & & & & & \\
0.087 & 0.113 & 0.086 & & & & & & \\
0.105 & 0.151 & 0.086 & 0.130 & & & & & \\
0.104 & 0.151 & 0.068 & 0.106 & 0.145 & & & & \\
0.094 & 0.094 & 0.053 & 0.069 & 0.082 & 0.102 & & & \\
0.059 & 0.087 & 0.059 & 0.061 & 0.064 & 0.043 & 0.054 & & \\
0.083 & 0.127 & 0.072 & 0.082 & 0.103 & 0.047 & 0.060 & 0.101 & & \\
0.119 & 0.152 & 0.083 & 0.126 & 0.103 & 0.077 & 0.056 & 0.081 & 0.162 \\
0.090 & 0.126 & 0.081 & 0.093 & 0.092 & 0.058 & 0.061 & 0.085 & 0.090 & 0.089
\end{array}\right)
$$




$$
B=\left(\begin{array}{llllllllll}
0.754 & & & & & & & \\
0.743 & 0.738 & & & & & & \\
0.755 & 0.747 & 0.761 & & & & & \\
0.752 & 0.745 & 0.756 & 0.755 & & & & \\
0.750 & 0.741 & 0.752 & 0.750 & 0.750 & & & & \\
0.744 & 0.737 & 0.747 & 0.744 & 0.744 & 0.740 & & & \\
0.741 & 0.732 & 0.744 & 0.741 & 0.739 & 0.733 & 0.731 & & \\
0.777 & 0.770 & 0.780 & 0.777 & 0.776 & 0.771 & 0.766 & 0.805 & \\
0.773 & 0.764 & 0.777 & 0.773 & 0.772 & 0.766 & 0.761 & 0.800 & 0.797 \\
0.745 & 0.736 & 0.749 & 0.745 & 0.742 & 0.737 & 0.734 & 0.769 & 0.766 & 0.739
\end{array}\right)
$$

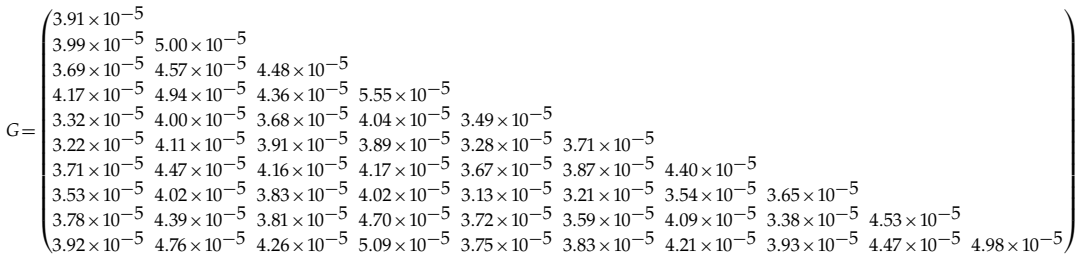

and $\eta_{t}=I\left(Y_{t}<0\right) \odot Y_{t}$, where $\odot$ denotes the Hadamard (elementwise) product.

By taking expectations, the matrix $C$ can be rewritten as $\bar{H} \odot\left(\iota^{\prime}-A-B\right)-\bar{N} \odot G$, where $\iota$ is a vector of ones, and $\bar{N}=E\left[\eta_{t} \eta_{t}^{\prime}\right]$ where $\bar{H}$ is the unconditional covariance matrix.

Then, the matrix $C$ is

$$
C=\left(\begin{array}{cccccccccc}
0.018 & & & & & & & & \\
0.005 & 0.055 & & & & & & & \\
-0.006 & 0.038 & 0.053 & & & & & & \\
0.002 & -0.001 & 0.011 & 0.023 & & & & & \\
-0.012 & 0.022 & 0.033 & 0.004 & 0.027 & & & & \\
-0.005 & 0.007 & 0.021 & 0.014 & 0.010 & 0.045 & & & \\
0.002 & -0.015 & -0.021 & 0.002 & -0.017 & -0.004 & 0.044 & & \\
0.011 & -0.022 & -0.012 & 0.012 & -0.017 & 0.013 & 0.011 & 0.043 & \\
-0.008 & 0.011 & 0.011 & -0.011 & 0.013 & 0.000 & -0.007 & -0.022 & 0.032 \\
0.006 & 0.015 & 0.012 & -0.001 & 0.003 & -0.007 & -0.008 & 0.002 & -0.006 & 0.015
\end{array}\right)
$$

Received November 16, 2009; revised July 25, 2012; accepted August 8, 2012.

\section{REFERENCES}

Alexander, C. 2001. Orthogonal GARCH. Mastering Risk 2: 21-38.

Alexander, C. and A. Chibumba. 1997. Multivariate Orthogonal Factor GARCH. University of Sussex, Mimeo. 
Asai, M., M. McAleer, and J. Yu. 2006. Multivariate Stochastic Volatility: a Review. Econometric Reviews 25(2): 145-175.

Barone-Adesi, G., F. Bourgoin, and K. Giannopoulos. 1998. Don't Look Back. Risk 11(8): 100-103.

Bauwens, L., S. Laurent, and J. V. K. Rombouts. 2006. Multivariate GARCH Models: a Survey. Journal of Applied Econometrics 21(1): 79-109.

Berkowitz, J. and J. O'Brien. 2002. How Accurate are Value-at-risk Models at Commercial Banks? The Journal of Finance 57(3): 1093-1111.

Bollerslev, T. 1986. Generalized Autoregressive Conditional Heteroskedasticity. Journal of Econometrics 31(3): 307-327.

Bollerslev, T. 1990. Modelling the Coherence in Short-run Nominal Exchange Rates: a Multivariate Generalized ARCH Model. Review of Economics and Statistics 72(3): 498-505.

Bollerslev, T., R. F. Engle, and J. M. Woodridge. 1988. A Capital Asset Pricing Model with Time-varying Covariances. The Journal of Political Economy 96(1): 116-131.

Boudoukh, J., M. Richardson, and R. Whitelaw. 1998. The Best of both Worlds. Risk 11(5): 64-67.

Brooks, C., and G. Persand. 2003. Volatility Forecasting for Risk Management. Journal of Forecasting 22(1): 1-22.

Cappiello, L., R. F. Engle, and K. Sheppard. 2006. Asymmetric Dynamics in the Correlations of Global Equity and Bond returns. Journal of Financial Econometrics 4(4): 537-572.

Christoffersen, P. 2009. "Value-at-risk Models". In T. G. Andersen, R. A. Davis, J.-P. Kreiss, and T. Mikosch, (eds.), Handbook of Financial Time Series. Berlin Heidelberg: Springer.

Christoffersen, P. F. 1998. Evaluating Interval Forecasts. International Economic Review 39(4): 841-862.

DeMiguel, V., L. Garlappi, and R. Uppal. 2009. Optimal Versus Naive Diversification: How Inefficient is the $1 / \mathrm{N}$ Portfolio Strategy? Review of Financial Studies 22(5): 1915-1953.

Ding, Z., C. W. J. Granger, and R. F. Engle. 1993. A Long Memory Property of Stock Returns and a New Model. Journal of Empirical Finance 1(1): 83-106.

Engle, R. 2002. Dynamic Conditional Correlation: a Simple Class of Multivariate Generalized Autoregressive Conditional Heteroskedasticity Models. Journal of Business \& Economic Statistics 20(3): 339-350.

Engle, R., and K. Sheppard. 2008. "Evaluating the Specification of Covariance Models for Large Portfolios". Working Paper, Department of Economics, University of Oxford.

Engle, R. F., and S. Manganelli. 2004. CAViaR: Conditional Autoregressive Value at Risk by Regression Quantiles. Journal of Business \& Economic Statistics 22(4): 367-382.

Engle, R. F., N. Shephard, and K. Sheppard. 2008. "Fitting vast Dimensional Timevarying Covariance Models". Discussion Paper Series n.403, Department of Economics, University of Oxford. 
Engle, R. F., and K. Sheppard. 2001. "Theoretical and Empirical Properties of Dynamic Conditional Correlation Multivariate GARCH". NBER Working Paper W8554.

Francq, C. and J. M. Zakoian. 2009. "A Tour in the Asymptotic Theory of GARCH Estimation". In T. G. Andersen, R. A. Davis, J.-P. Kreiss, and T. Mikosch (eds.), Handbook of Financial Time Series. Berlin Heidelberg: Springer.

Giacomini, R., and I. Komunjer. 2005. Evaluation and Combination of Conditional Quantile Forecasts. Journal of Business \& Economic Statistics 23(4): 416-431.

Giacomini, R., and H. White. 2006. Tests of Conditional Predictive Ability. Econometrica 74(6): 1545-1578.

Glosten, L., R. Jagannathan, and D. Runkle. 1993. On the Relation Between the Expected Value and the Volatility of the Nominal Excess Return on Stocks. Journal of Finance 48: 1779-1801.

Harvey, A., E. Ruiz, and N. Shephard. 1994. Multivariate Stochastic Variance Models. Review of Economic Studies 61(2): 247-264.

Hentschel, L. 1995. All in the Family: Nesting Symmetric and Asymmetric GARCH Models. Journal of Financial Economics 39(1): 71-104.

Hull, J., and A. White. 1998. Incorporating Volatility Updating into the Historical Simulation Method for Value-at-risk. Journal of Risk 1(1): 5-19.

Koenker, R. 2005. Quantile Regression. Cambridge: Cambridge University Press.

Kupiec, P. H. 1995. Techniques for Verifying the Accuracy of Risk Measurement Models. The Journal of Derivatives 3(2): 73-84.

McAleer, M. 2009. The ten Commandments for Optimizing Value-at-risk and Daily Capital Charges. Journal of Economic Surveys 23(5): 831-849.

McAleer, M., and B. da Veiga. 2008. Single-Index and Portfolio Models for Forecasting Value-at-risk Thresholds. Journal of Forecasting 27(3): 217-235.

Nelson, D. B. 1991. Conditional Heteroskedasticity in Asset Returns: a New Approach. Econometrica 59(2): 347-370.

Nijman, T., and E. Sentana. 1996. Marginalization and Contemporaneous Aggregation in Multivariate GARCH Processes. Journal of Econometrics 71(1): 71-87.

Pesaran, B., and M. H. Pesaran. 2010. Conditional Volatility and Correlations of Weekly Returns and the VaR Analysis of 2008 Stock Market Crash. Economic Modelling 27: 1398-1416.

Pesaran, M. H., C. Schleicher, and P. Zaffaroni. 2009. Model Averaging in Risk Management with an Application to Futures Markets. Journal of Empirical Finance 16(2): 280-305.

Straumann, D., and T. Mikosch. 2006. Quasi-MLE in Heteroscedastic Times Series: a Stochastic Recurrence Equations Approach. Annals of Statistics 34: 2449-2495.

Tse, Y. K., and A. Tsui. 2002. A Multivariate Generalized Autoregressive Conditional Heteroscedasticity Model with Time-Varying Correlations. Journal of Business $\mathcal{E}$ Economic Statistics 20(3): 351-362.

Zaffaroni, P. 2007. Contemporaneous Aggregation of GARCH Processes. Journal of Time Series Analysis 28(4): 521-544. 